\title{
WestVirginiaUniversity
}

THE RESEARCH REPOSITORY @ WVU

Graduate Theses, Dissertations, and Problem Reports

2017

\section{Fear of Pain and Dental Care-Related Fear: Associations with the MC1R Gene}

\author{
Cameron L. Randall
}

Follow this and additional works at: https://researchrepository.wvu.edu/etd

\section{Recommended Citation}

Randall, Cameron L., "Fear of Pain and Dental Care-Related Fear: Associations with the MC1R Gene" (2017). Graduate Theses, Dissertations, and Problem Reports. 6474.

https://researchrepository.wvu.edu/etd/6474

This Dissertation is protected by copyright and/or related rights. It has been brought to you by the The Research Repository @ WVU with permission from the rights-holder(s). You are free to use this Dissertation in any way that is permitted by the copyright and related rights legislation that applies to your use. For other uses you must obtain permission from the rights-holder(s) directly, unless additional rights are indicated by a Creative Commons license in the record and/ or on the work itself. This Dissertation has been accepted for inclusion in WVU Graduate Theses, Dissertations, and Problem Reports collection by an authorized administrator of The Research Repository @ WVU.

For more information, please contact researchrepository@mail.wvu.edu. 
Fear of Pain and Dental Care-Related Fear: Associations with the $M C 1 R$ Gene

Cameron L. Randall, M.S.

\author{
Dissertation submitted \\ to the Eberly College of Arts and Sciences \\ at West Virginia University \\ in partial fulfillment of the requirements for the degree of \\ Doctor of Philosophy in \\ Psychology
}

\author{
Daniel W. McNeil, Ph.D., Chair \\ Melissa Blank, Ph.D. \\ Richard Jurevic, D.D.S., Ph.D. \\ Kevin T. Larkin, Ph.D. \\ John R. Shaffer, Ph.D. \\ Department of Psychology
}

Morgantown, West Virginia

2017

Keywords: dental fear; fear of pain; genetics; melanocortin-1 receptor; MC1R; behavioral genetics; behavioral dentistry

Copyright 2017 Cameron L. Randall 


\begin{abstract}
Fear of Pain and Dental Care-Related Fear: Associations with the MC1R Gene
\end{abstract}

Cameron L. Randall, M.S.

Fear of pain is experienced in acute and chronic pain populations, as well as generally, and impacts numerous aspects of the pain experience, including pain intensity, pain-related disability, and pain behavior (e.g., avoidance). A related but separate construct, dental care-related fear, also is experienced in the general population, and impacts dental treatment-seeking behavior and oral and systemic health. Very minimal work has addressed the role of genetics in the etiologies of fear of pain and dental care-related fear. Limited available data suggest that variants of the melanocortin-1 receptor $(M C 1 R)$ gene may predict greater levels of dental care-related fear. The $M C 1 R$ gene also may be important in the etiology of fear of pain. This study aimed to confirm that $M C 1 R$ variant status predicts dental care-related fear and to determine, for the first time, whether $M C 1 R$ variant status predicts general fear of pain. Participants were 817 Caucasian adults $(62.5 \%$ female, $M$ age $=34.7$ years, $S D=8.7)$ who were part of a larger, cross-sectional project that sought to identify determinants of oral diseases at the community-, family-, and individual levels (Center for Oral Health Research in Appalachia, cohort 1; COHRA1).

Participants were genotyped for SNPs on $M C 1 R$ and completed self-report measures of fear of pain and dental care-related fear. Variation on $M C 1 R$ predicted higher levels of dental carerelated fear and fear of pain. Importantly, fear of pain mediated the relation between $M C 1 R$ variant status and dental care-related fear, $\mathrm{B}=1.60,95 \% \mathrm{CI}[0.281,3.056] . M C 1 R$ variants may influence orofacial pain and, in turn, predispose individuals to develop fears about pain. Such fears influence the pain experience and associated pain behaviors, as well as fears about dental treatment. This study provides support for small genetic contributions to the development/maintenance of fear of pain and dental care-related fear. These findings suggest directions for future research to identify potential targets for intervention in the treatment of fear of pain and dental care-related fear. 
Table of Contents

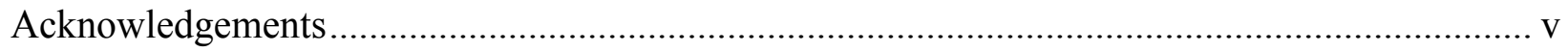

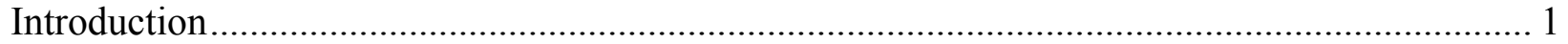

Role of Genetics in Fear of Pain and Dental Care-Related Fear ............................................. 1

Melanocortin-1 Receptor Gene, Pain, and Anxiety ...................................................... 4

Understanding Fear of Pain: A Biopsychosocial Perspective ............................................... 7

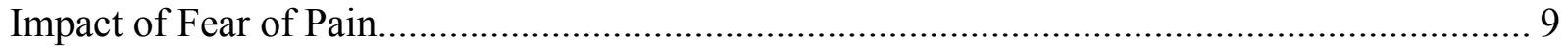

Fear of Pain and its Relation to Dental Pain.......................................................................... 11

Fear of Pain is a Critical Component of Dental Care-Related Fear....................................... 12

Understanding Dental Care-Related Fear and Anxiety: Conceptual and Etiological Issues .... 13

Impact of Dental Care-Related Fear ...................................................................... 17

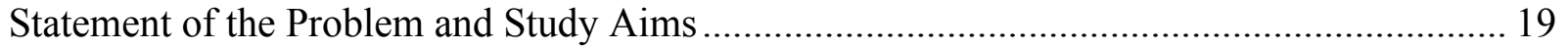

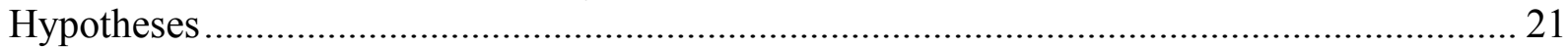

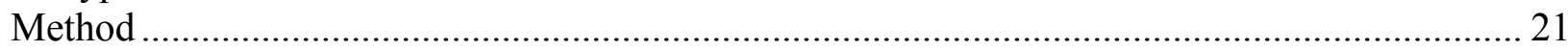

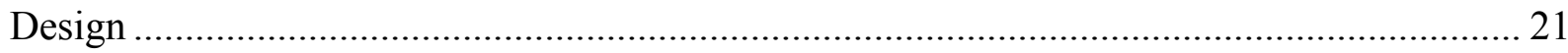

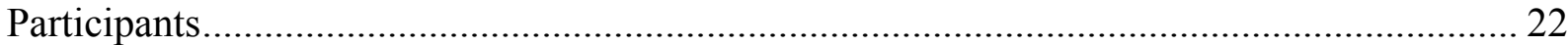

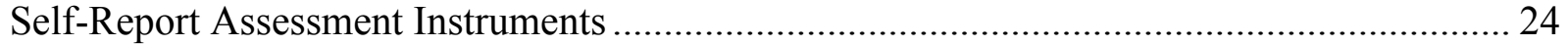

Demographic questionnaire ................................................................................... 24

Fear of Pain Questionnaire-9 ................................................................................. 24

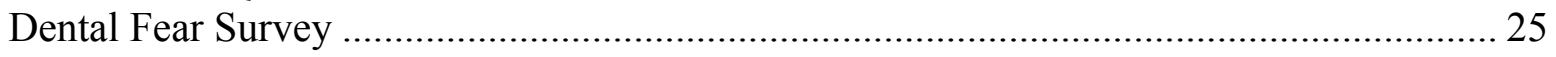

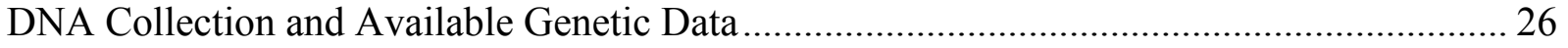

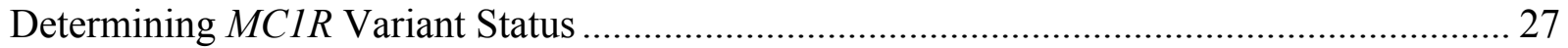

Determining MC4R, OPRM1, COMT, and SCN9A Variant Status ..................................... 28

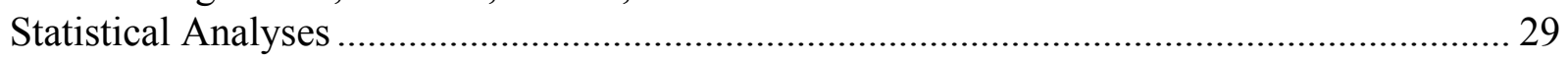

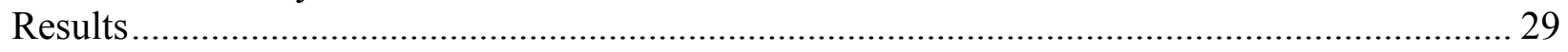

Sample Characteristics, Fear of Pain, and Dental Care-Related Fear................................... 29

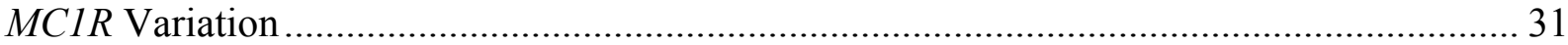

$M C 1 R$ Variation, Fear of Pain, and Dental Care-Related Fear......................................... 31

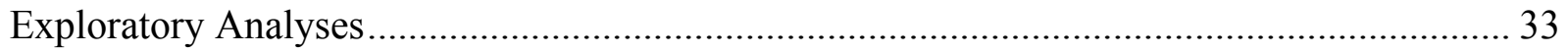

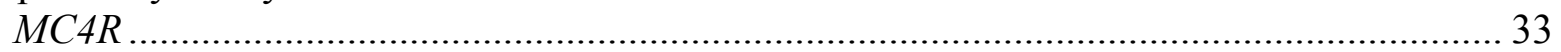

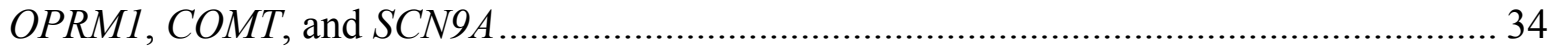

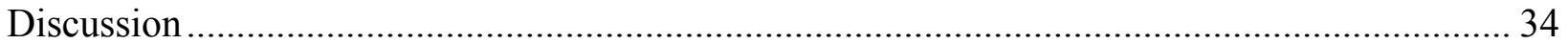

Comment on Results of Exploratory Analyses ............................................................... 37

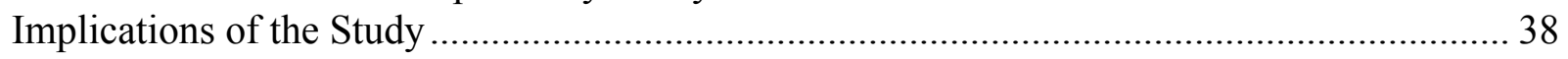

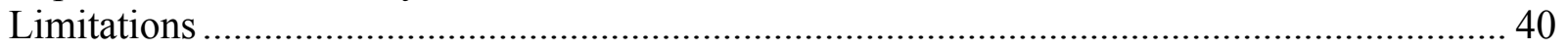

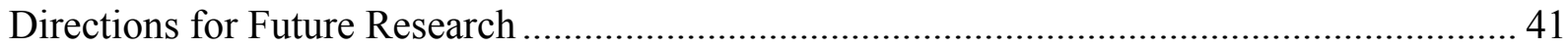

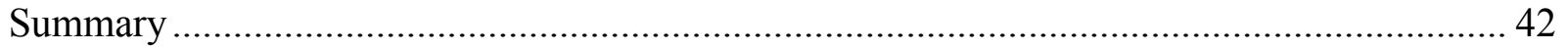

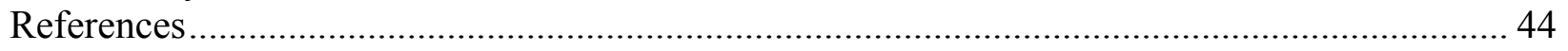

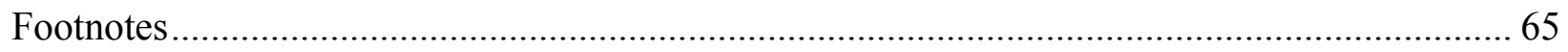

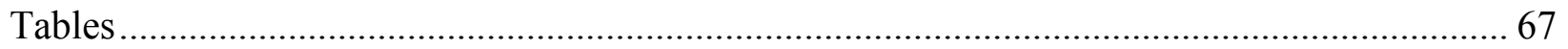

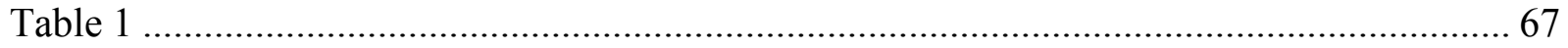

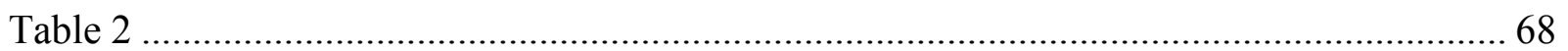

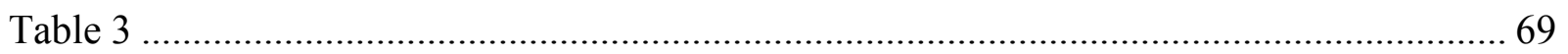

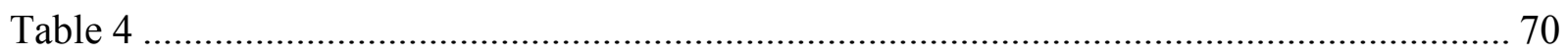

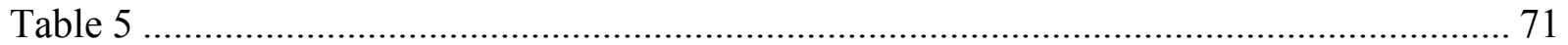

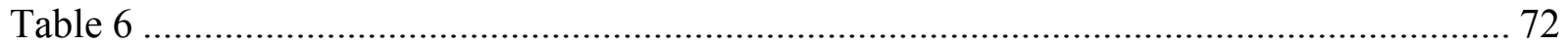




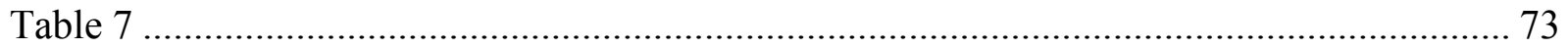

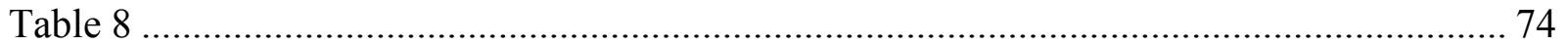

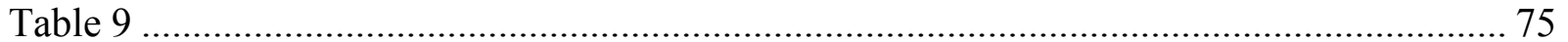

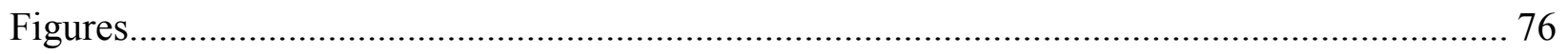

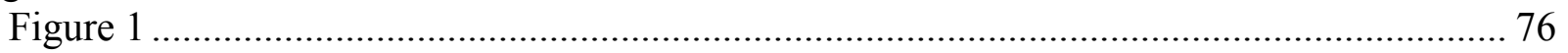

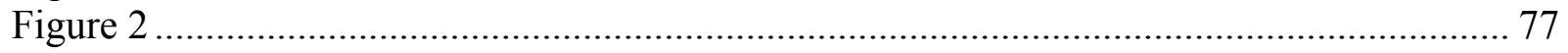

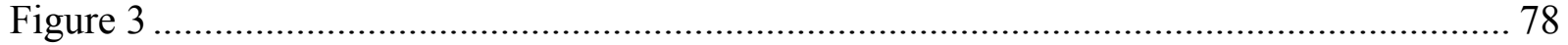

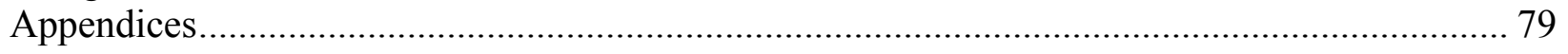

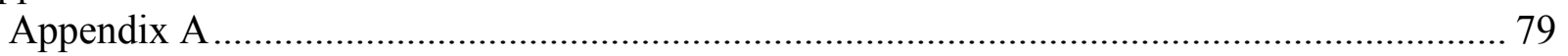

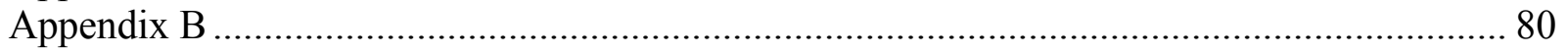

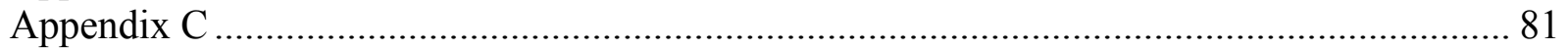

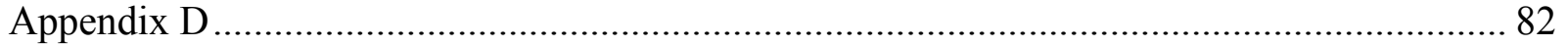




\section{Acknowledgements}

Completion of the dissertation marks an exciting final milestone in my doctoral training, and carrying out this project has been edifying. In addition to learning a great deal more about anxiety, pain, genetics, statistics, and data management, I have gained important knowledge about how to engage in transdisciplinary work and to how to participate in team science. Such a learning experience bookends what has been an incredible journey to the $\mathrm{PhD}$.

My time at West Virginia University has been special, indeed. The Department of Psychology has encouraged me to think critically as a student, clinician, and scientist; I have been intellectually stimulated at all stages of my development. During my training, I was pushed to grow broadly and deeply as a thinker and was embraced with enthusiasm by my professors and classmates. The culture of the Department and the investment of its faculty created, for me, an intellectually stimulating environment and provided rich and individualized science training experiences. I am grateful for the opportunity to train at West Virginia University, where a strong behavioral orientation has profoundly informed my theoretical and scientific understanding of the human experience, generally, and pain, fear, and anxiety, specifically. I am excited to build on this training as I develop an independent program of research.

I acknowledge with gratitude the participants of the Center for Oral Health Research in Appalachia (COHRA) study that is the topic of this dissertation. I also acknowledge the COHRA investigators and staff, especially the Executive Committee - Richard J. Crout, DMD, PhD, Mary L. Marazita, PhD, Daniel W. McNeil, PhD, and Robert J. Weyant, DMD, DrPH - who have been helpful and supportive in the completion of this project. The data presented here were collected with the support of funding from the National Institute of Dental and Craniofacial Research (National Institutes of Health; R01-DE014899). A Ruth L. Kirschstein National 
Research Service Award for Individual Predoctoral Fellows (F31-DE023493) from the same Institute supported training experiences in statistical genetics that allowed me to complete study analyses. I am appreciative of the opportunity to have presented preliminary results at the National Institute of Dental and Craniofacial Research's 2015 Trainee Spotlight and for the recognition of this work by the Behavioral, Epidemiologic, and Health Services Research Group of the International Association for Dental Research. I am also appreciative of the Journal of Dental Research for publishing this study, in part, in their Special Issue on Orofacial Pain (see Randall et al., 2016a).

I am deeply appreciative of the time and guidance provided by the members of the dissertation committee: Melissa Blank, Richard (Rick) Jurevic, Kevin Larkin, Daniel (Dan) McNeil, and John Shaffer. Melissa has challenged me to think about the role of genetics in complex behavioral phenotypes and has offered a great deal of support during my graduate training. Rick has encouraged me to think about the role of psychology in dentistry and the integration of research in the two disciplines. Kevin provided exceptional training in research methods in clinical psychology and has been a constant source of support and intellectual stimulation during my time at West Virginia University. And, John has provided expertise and training in statistical genetics and has supported me immensely as I worked to bridge genetics and behavioral dentistry; it has been a pleasure to work with him on interdisciplinary science.

Dan deserves special recognition, as I could not imagine having a more intelligent, vibrant, encouraging, kind, and empathetic mentor. Dan is one of the most passionate and invested scientists and professors I have known, and it is a privilege to have worked with him for the last six years. I will carry with me fond memories of engaging conversations about science and sage professional advice. Dan's curiosity and enthusiasm about his work is infectious, and 
I'm happy to have caught the "bug." His belief that our work should be in the service of others especially those who are suffering, disenfranchised, or disproportionally impacted by health disparities - has become a driving motivator of my own work. I have learned so much from my primary mentor and dear friend, and have felt professionally and personally supported at every turn. Of course, I have had many mentors, advocates, role models, and teachers along this journey, but my success in graduate school is thanks, in such a large part, to Dan.

I must also acknowledge the support of my labmates and classmates. Fellow Anxiety, Psychophysiology, and Pain Research Laboratory members have enriched my time in graduate school and have helped me to get the most out of my scientific pursuits. My cohort, especially Patty Bamonti, Colleen Lillard, Philip Lemaster, Janelle Mentrikoski, Nipat Bock, and Ria Travers, challenged me to be a better scientist and clinician and provided the most consistent positivity and encouragement a PhD student could ask for. My labmate and best friend Sarah Hayes Addicks deserves special appreciation; she entertained me with deeply thought-provoking conversations and informed my thinking about mental health, public health, leadership, and the complex systems in which we find ourselves. She also provided unconditional support and empathy and many, many fond memories. Lastly, I acknowledge the deep support of my parents, David and Debbie, and my sister, Alyssa. My family has been such a source of positivity, energy, and motivation, which has made this journey a good one. Thanks for encouraging my never-ending schooling! 
Fear of Pain and Dental Care-Related Fear: Associations with the MC1R Gene

Fear of pain and dental care-related fear ${ }^{1}$ both are well-studied phenomena, each ubiquitous and with far-reaching and important effects on health behavior. Fears about pain and injury are the third most commonly reported of all fears (Oosterink, de Jongh, \& Hoogstraten, 2009), and fear of pain is associated with pain-related disability, pain intensity, and pain behavior, among other aspects of the pain experience, across medical and general populations (e.g., Buer \& Linton, 2002; Crombez, Vlaeyen, Heuts, \& Lysens, 1999; McCracken, Gross, Aikens, \& Carnkike, 1996). Fears about dental treatment, related to but distinct from fear of pain, is similarly prevalent; in the United States of America, close to half of the population reports experiencing at least moderate levels of dental care-related fear (Dionne, Gordon, McCullagh, \& Phero, 1998), with between 5 and 10 percent of adults reporting avoidance of necessary dental treatment as a result of this fear (Milgrom, Weinstein, \& Heaton, 2009). Avoidance behaviors associated with both fear of pain and dental care-related fear detrimentally impact physical and psychological wellbeing (e.g., Crofts-Barnes, Brough, Beddis, \& Girdler, 2010; Schuller, Willumsen, \& Holst, 2003; Verbunt, Seelen, \& Vlaeyen, 2004). Critical to reducing the burden of these phenomena is a more complete conceptualization of their etiologies. Minimal extant literature addresses the role of genetics in the etiology of dental care-related fear and, at this time, only one known study addresses the influence of genetic factors on the development and maintenance of general fear of pain. Knowledge in this area has the potential to significantly impact these public health concerns.

\section{Role of Genetics in Fear of Pain and Dental Care-Related Fear}

Biological factors likely play a role in the development and maintenance of fear in some individuals. Contemporary psychology, including behavioral neuroscience, acknowledges the 
importance of biological and genetic factors as predisposing individuals to be more or less likely to develop psychopathology, including problems such as dental care-related fear (McNeil \& Randall, 2014). Genetic differences may influence across several domains (e.g., anxiety sensitivity, fear conditioning, cognitive vulnerability, pain sensitivity) whether and how an individual acquires fears about pain and/or dental treatment. To be sure, the role of genetics in fear and anxiety is becoming better understood, as much research has focused on the topic.

Over the last several decades, genetics has received much attention in the psychopathology literature (Malouff, Rooke, \& Schutte, 2008). Even before then, researchers aimed to understand how genetic factors affect human behavior, more widely (Malouff et al., 2008). The earliest work of this type in the area of anxiety involved family studies, which provided evidence that anxiety disorders specifically, and probably fear and anxiety more generally, have a high degree of familial aggregation (Smoller, Block, \& Young, 2009). Later, twin studies offered fairly definitive evidence that anxiety disorders are heritable (Hettema, Neale, \& Kendler, 2001; Smoller et al., 2009) and demonstrated that, while important, environment does not completely account for observed familial aggregation. Across anxiety disorders, the degree of heritability appears to be relatively high, with estimates ranging from 2051\% (e.g., Distel et al., 2008; Maron, Hettema, \& Shlik, 2008; Smoller et al., 2009; Timpano, Hasler, Riccardi, Murphy, \& Schmidt, 2009). Work in behavioral genetics (e.g., Farmer, Eley, \& McGuffin, 2005; Jang \& Shikishima, 2009) has targeted the genetic underpinnings of anxiety disorders, as well as gene-environment interactions, and several genes and associated pathways have been implicated as important in the pathogenesis of disorders related to fear and anxiety (e.g., Hudson \& Pope, 2007; van Eekelen et al., 2011). 
Genetic variation certainly is responsible, in part, for individual differences in problematic fear and anxiety, generally. Genetic factors can serve as a diathesis for high levels of fear via several routes (McNeil \& Randall, 2014). With regard to fear of pain, the only known study to address genetic factors suggests that there is a moderate degree of heritability (i.e., $34 \%$ in a family-based cohort study of adolescents and adults; Randall et al., 2016b). A similar degree of heritability was observed for dental care-related fear in the same sample (30\%), and the genetic correlation between dental care-related fear and fear of pain was substantial ( $(\mathrm{hhoG}=$ 0.67), providing biological evidence that the two are related but distinct constructs (Randall et al., 2016b). The first known study of the heritability of dental care-related fear utilized twin study methodology in a sample of adolescents and estimated heritability to be moderately high for both boys and girls (30-47\%; Ray et al., 2010). In another twin study of dental care-related fear, moderate heritability (41\%) also was found in a sample comprised of individuals aged 2335 years (Vassend et al., 2011). In that study, there was a high degree of genetic correlation between dental care-related fear and the personality trait neuroticism, leading the authors to suggest that the two phenotypes are distinct but may share similar etiologies. A genetic predisposition for higher neuroticism may have a cascade effect on dental care-related fear. Together, these limited data provide evidence that genetic factors may be especially important in understanding the observed intergenerational transmission of dental care-related fear (e.g., Lara, Crego, \& Romero-Maroto, 2012; McNeil, Randall, Crout, Weyant, Marazita, 2014).

Extending the conclusions drawn by the results of these heritability studies, candidate gene analysis recently has been applied to research on dental care-related fear. Long has been clinical lore that patients with red hair are more sensitive to pain, less likely to experience analgesia following lidocaine injections, and more likely to be fearful or anxious about 
medical/dental treatment than their blonde-, brown-, or black-haired counterparts (e.g., Flaherty, 2010; Thompson, 2011). Such anecdotes seem to interest the general population, as discussion of the topic has appeared in high-profile lay press publications like National Geographic (Conant, 2014) and TIME (Melnick, 2010), perpetuating the story. Given this lore, and that variants in the melanocortin-1 receptor $(M C 1 R)$ gene cause redheadedness, Binkely and colleagues (2009) studied the role of the $M C 1 R$ gene in dental care-related fear and fear of dental pain. Working under the assumption that resistance to local anesthesia may result in more painful dental experiences, which may condition fears of dental pain and dental treatment, the researchers tested whether having $M C 1 R$ gene variants was associated with fear of dental pain, dental carerelated fear, and avoidance of dental care. Results suggested that $M C 1 R$ gene variant status (i.e., having one or more gene variants versus no variants) predicts greater fear of dental pain and dental care-related fear $\left(R^{2}=.18\right)$, as well as a two-fold increase in the likelihood of avoiding dental care. This single study suggests that the $M C 1 R$ gene may be particularly important for understanding individual differences in dental care-related fear. Given the well-evidenced relation between dental care-related fear and fear of pain, more generally, results from the Binkely et al. (2009) study provide reason to study the potential association between the $M C 1 R$ gene and general fear of pain and provide a model for completing candidate gene analysis in the dental care-related fear and fear of pain arenas.

\section{Melanocortin-1 Receptor Gene, Pain, and Anxiety}

Melanocortins are hormones derived from the proopiomelanocortin gene, and refer to adrenocorticotropin (ACTH) and $\alpha$-, $\beta$-, and $\gamma$-melanocyte-stimulating hormones (Chaki \& Okuyama, 2005). These hormones have been implicated in various physiological functions, such as memory and learning (de Wied \& Jolles, 1982), analgesia (Vrinten, Adan, Groen, \& Gispen, 
2001; Vrinten, Gispen, Groen, \& Adan, 2000), stress responses (Adan et al., 1999; von Frijtag, Croiset, Gispen, Adan, \& Wiegant, 1998), and inflammation (Ceriani, Mcalus, Catania, \& Lipton, 1994), among others (see Chaki \& Okuyama, 2005). Five receptors are activated by melanocortins (MC1R-MC5R), each coded for by different genes, and contributing to different physiological functions (Chaki \& Okuyama, 2005). MC1R plays a major role in skin pigmentation, and so variations in the $M C 1 R$ gene, which is on chromosome 16, are associated with skin fairness and red hair color (Raimondi et al., 2008). It has been suggested that the $M C 1 R$ gene also plays a role in other phenotypes. For instance, across people of all pigmentation, the expressed gene has been found in brain tissue of the pathways responsible for the experience and processing of pain, anxiety, and fear (Chaki \& Okuyama, 2005; Xia, Wikberg, \& Chhajlani, 1995), fitting with evidence that suggests that the related $M C 4 R$ gene and the melanocortinergic pathway are important in anxiety behavior (Chaki \& Okuyama, 2005; Liu et al., 2007).

Generally speaking, genetic variation seems to account for small to moderate amounts of variance in pain perception, with various pathways and mechanisms proposed (see Shi, Cleeland, Klepstad, Miaskowski, \& Pedersen, 2010; Vasileiou, Giaginis, Klonaris, \& Theocharis, 2009). Moreover, differences in pain perception across pain types or modalities, within the same individual, appear to involve a genetic component (Nielsen et al., 2008). For example, in addition to the MCIR gene (e.g., Mogil et al., 2005), several genes have been identified as potentially important in the pain experience, such as the $S C N 9 A$ (e.g., Drenth \& Waxman, 2007), OPRM1 (e.g., Fillingim et al., 2005), and COMT genes (e.g., Diatchenko et al., 2005; Zubieta et al., 2003). Animal studies provide strong support that the melanocortin system plays a role in nociception (e.g., Beltramo et al., 2003). Specifically, MC1R, and thus the $M C 1 R$ gene, appear to 
play a significant role in acute pain perception, a role that may be sex-specific (e.g., female, but not male, mice lacking MC1R demonstrate increased tolerance to thermal pain; Delaney, Keighren, Fleetwood-Walker, \& Jackson, 2010). Research with humans has yielded similar results as the translational work with animals; $M C 1 R$ genotype affects pain sensitivity, including dental pain sensitivity (Liem, Joiner, Tsueda, \& Sessler, 2005; Mogil et al., 2005), with several single nucleotide polymorphisms (SNPs) identified as particularly important (García-Borrón, Sánchez-Laorden, \& Jiménez-Cervantes, 2005). Related to pain perception, $M C 1 R$ gene variants are associated with reduced efficacy of and increased need for general and local (including dental) anesthesia (e.g., Liem et al., 2004; Liem et al., 2005; Myles, Buchanan, \& Bain, 2012). $M C 1 R$ expression and presence of $\mathrm{MC} 1 \mathrm{R}$ has been identified in periaqueductal gray matter cells (Xia et al., 1995), the primary control center for descending pain modulation. There are no known relevant data indicating the mechanism by which MC1R is associated with pain perception nor the downstream effects of $M C 1 R$ variation on protein function as related to pain experience. However, it has been suggested that central MC1R involvement and/or peripheral dysfunction activates central MC4Rs to impact pain sensitivity (Andresen, Lunden, Drewes, \& Arendt-Nielsen, 2011), which may partly explain why $M C 1 R$ variation is correlated with hypersensitivity to pain.

These data lend themselves to the development of two predictions regarding the relation between $M C 1 R$ gene variant status and dental care-related fear: (1) $M C 1 R$ gene variants produce heightened pain sensitivity, which may result in more readily conditioned fear of pain and dental care-related fear, and/or (2) reduced anesthesia efficacy associated with $M C 1 R$ gene variants results in more painful dental procedures, which may lead to the conditioning of fear of pain and dental care-related fear (Binkely et al., 2009). While such explanatory mechanisms are likely 
(and testable), it may also be the case that variants in the $M C 1 R$ gene impact anxiety generally, including fears and anxieties about pain and dental treatment. The melanocortin pathway (and notably MC4R) is involved in emotional stress-induced anxiety and activation of the hypothalamo-pituitary-adrenal axis (Cragnolini, Schiöth, \& Scimonelli, 2005; Liu, Garza, Li, \& Lu, 2013), and anxiety and depression more broadly (Chaki \& Okuyama, 2005). Thus, the related MC1R (and the $M C 1 R$ gene) may be important in understanding anxieties and fears such as fear of pain and dental care-related fear. Given that the $M C 1 R$ and $M C 4 R$ genes are expressed in similar regions of the brain (Xia et al., 1995), more research on the less-studied MC1R gene is necessary in order to determine its potential role in both general and specific fears/anxieties.

\section{Understanding Fear of Pain: A Biopsychosocial Perspective}

Pain has been described as "an unpleasant sensory and emotional experience associated with actual or potential tissue damage, or described in terms of such damage" (International Association for the Study of Pain Task Force on Taxonomy, 1994, p. 211). Indeed, pain is complex, and biological predisposition and learning history shape idiosyncratic pain experiences (International Association for the Study of Pain Task Force on Taxonomy, 1994). Under a multidimensional and biopsychosocial framework, it has been suggested that several factors influence an individual's experience of pain. Specifically, Turk and Flor (1999, p. 20) have asserted that "predispositional factors and current biological factors may initiate, maintain, and modulate physical perpetuations; predispositional and current psychological factors influence the appraisal and perception of internal physiological signs; and social factors shape the behavioral responses of patients to the perceptions of their physical perturbations."

Given the affective nature of pain, the experience involves a significant psychological component. A large body of research suggests that emotions, especially fear and anxiety, play an 
important role in the experience of pain (e.g., Geisser et al., 1994, McCracken, Zayfert, \& Gross, 1992). For example, in several contexts, fear is associated with reports of higher levels of experienced pain (e.g., Fillingim, 2000; Fillingim, Keefe, Light, Booker, \& Maixner, 1996; Fillingim, King, Ribeiro-Dasilva, Rahim-Williams, \& Riley, 2009; van Wijk, de Jongh, Lindeboom, 2010; van Wijk \& Hoogstraten, 2009). Similarly, perceived control is predictive of pain tolerance and threshold and may reduce autonomic arousal in instances of acute pain stimulation (Feldner \& Hekmat, 2001; Geer, Davison, \& Gatchel, 1970). Given the clear relation between fear/anxiety and pain perception, several researchers and theoreticians have suggested that fear of pain, specifically, may be a particularly important variable in the experience of pain, and notably in regard to avoidance and other pain behaviors.

Fear of pain involves irrational dread or apprehension about nociception resulting from any of a variety of sources (e.g., breaking a bone, falling, receiving an injection, chronic musculoskeletal pain; see Asmundson, Vlayen, \& Crombez, 2004). A model put forth by Asmundson, Norton, and Vlaeyen (2004) proposes that the fear is directed not just at the paininducing stimuli, but also experiences or behaviors that an individual previously has associated with pain. As with fears, generally, fear of pain presents as responses in three domains physiological, behavioral, and cognitive - with idiosyncratic presentation across individuals, and interaction between the responses (Asmundson et al., 2004; Lang, 1968). In other words, fear of pain, as manifested across the three response systems, influences and is influenced by the perception of pain, physiologic reactivity to pain sensations, pain behavior (e.g., avoidance, reassurance seeking, help seeking), and cognitions about the pain (e.g., catastrophizing, misappraisals, misattributions). Several models of the pain experience, the pain-avoidance 
relation, and fear of pain outline the connections between these variables (see Asmundson et al., 2004).

\section{Impact of Fear of Pain}

Across clinical and non-clinical populations, and with regard to both chronic and acute pain, fear of pain can have a profound impact on individual behavior. For example, it has been suggested that fear of pain operates to maintain chronic pain over time; even after a muscle or tissue injury has healed, avoidance behavior is perpetuated by fear of pain and results in deconditioning (e.g., muscle tissue loss, weight gain, decreased strength; Asmundson, Vlaeyen, \& Crombez, 2004). In a pain-avoidance cycle, avoidance behavior is reinforced when this deconditioning leads to further pain and negative experiences (Asmundson et al., 2004). Thus, a vicious cycle is set up such that fear of pain perpetuates and is exacerbated by the experience of chronic pain.

Fear of pain has been well studied in chronic pain populations (e.g., Hursey \& Jacks, 1992; Lee, Chiu, \& Lam, 2007; Turk, Robinson, \& Burwinkel, 2004; Vlaeyen, de Jongh, Geilen, Heuts, \& van Breuklen, 2001). Fear of pain is associated with or predicts several negative aspects of the chronic pain experience. For example, fear of pain is positively associated with pain intensity across several chronic pain populations (e.g., low back pain, headache; Asmundson, Norton, \& Veloso, 1999; Vlaeyen et al., 2001). Fears about pain also are highly associated with reduction in physical activity and normal movement in people suffering from chronic low back pain (Verbunt, Seelen, \& Vlaeyen, 2004). Additionally, fear of pain is the strongest predictor of disability and poor behavioral performance in individuals experiencing chronic pain (Crombez et al., 1999). Moreover, specific fears about pain versus more general fears or anxieties are associated with maladaptive pain behaviors - notably avoidance, 
complaining, and help-seeking - in individuals with chronic pain (McCracken et al., 1996).

Studies assessing cognitive performance and attention bias in chronic pain samples have suggested that information processing systems may be significantly influenced by fear of pain, such that hypervigilance to pain-related stimuli is borne out of fear of pain and maintains pain behaviors, notably avoidance (Asmundson, Kuperos, \& Norton, 1997; van Damme, Crombez, Eccleston, \& Roelofs, 2004). In individuals with chronic pain, fear of pain also may be a critical part of the mechanism responsible for the relation between anxiety sensitivity and the pain experience (Ocaňez, McHugh, \& Otto, 2010; Zvolensky, Goodie, McNeil, Sperry, \& Sorrell, 2001).

The role of fear of pain in non-clinical samples and in the experience of acute pain has been studied less than in chronic pain samples; however, extant data suggest that fear of pain exists in the general population (Buer \& Linton, 2002) and impacts the perception of acute pain across experimental and naturalistic contexts. For instance, self-reported pain intensity is positively associated with fear of pain in cases in which nociception is experimentally induced in healthy participants using ischemic, electrical, or thermal pain tests (George, Dannecker, \& Robinson, 2006; Roelofs, Peters, Deutz, Spijker, Vlaeyen, 2005). Using a cold pressor paradigm to experimentally induce pain sensations in a non-clinical sample, fear of pain has been found to predict self-reported pain intensity over and above catastrophizing (Hirsh, George, Binlosky, \& Robinson, 2008). Early work suggests that the ventral lateral frontal region, responsible for response regulation, and the anterior and posterior cingulate regions, associated with monitoring and evaluation of affective responses, may be the parts of the brain that are particularly important in the relation between fear of pain and acute pain perception (Ochsner et al., 2006). Fear of pain has been found to predict not only self-reported pain intensity, but also degree of disability, using 
an experimental paradigm that involved exercise-induced musculoskeletal injury (Parr et al., 2012). Likewise, in a sample of individuals experiencing acute low back pain, fear of pain was negatively associated with change in disability, even after controlling for pain intensity (George, Fritz, \& McNeil, 2006). Together, the evidence from studies utilizing clinical and non-clinical samples, across acute and chronic pain experience, suggests that fear of pain undoubtedly plays a critical role in the perception of nociception and in an individual's behavioral response to pain.

\section{Fear of Pain and its Relation to Dental Pain}

Though the literature is limited, experimental evidence suggests that sensitivity to one type of pain is not necessarily a good indication of sensitivity to other types of pain. For example, individuals often demonstrate varying degrees of pain tolerance and threshold across different types of experimentally-induced pain (i.e., thermal versus pressure versus electrical stimulation; Janal, Glusman, Kuhl, \& Clark, 1994). Complicating our understanding of nociception even further, it is clear that individuals demonstrate varying pain sensitivity across organ systems and regions of the body, with psychological variables playing a role. Notably, dental pain sensitivity appears to be related to, but distinct from, pain sensitivity in other parts of the body. For instance, Kelpac, Dowling, and Hauge (1982) found significant differences in dental pain tolerance, but not non-dental pain tolerance, between individuals who were and were not fearful of dental treatment.

Indeed, the experience of oral/dental pain is unique, compared to bodily pain in other areas, and even is described differently by individuals who are in pain (e.g., Grushka \& Sessle, 1984; McNeil, Vargovich, Sorrell, \& Vowles, 2014). Several factors may be important for the difference between dental and other pain, such as the way in which teeth are innervated compared to innervation of other parts of the body (Fried, Sessle, \& Devor, 2001; Hildebrand, 
Fried, Tuisku, \& Johansson, 1995; McNeil et al., 2014). Though dental professionals concern themselves with pain conditions of the hard and soft tissues of the head, face, neck, and intraoral cavity, collectively understood as orofacial pain (de Leeuw, 2008), dental pain often is conceptualized by others as toothache, injury to the teeth or jaw, or pain related to dental procedures (e.g., restoration, extraction, endodontic therapy; McNeil et al., 2014). Dental pain commonly is experienced, manifests in a variety of ways, and can be influenced by numerous biological, psychological, social, and environmental factors (McNeil et al., 2014).

Few studies have addressed the relation between fear of pain and perceived orofacial or dental pain; however, available data suggest that, like other types of pain, fear of pain impacts the experience of orofacial pain. The earliest work in the area provided evidence that orofacial pain patients, compared to matched healthy controls, report greater levels of general fear of pain, especially fear of severe pain (McNeil et al., 2001). Fear of dental pain, specifically, has been positively associated with experiencing greater duration and intensity of pain resulting from an intraoral injection (van Wijk \& Hoogstraten, 2009). Not surprisingly, individuals who have experienced dental pain overestimate fear of specific dental pains (van Wijk \& Hoogstraten, 2005). Though additional work is necessary to more definitively demonstrate a link between fear of pain and dental pain specifically, existing literature indicates that fear of dental pain and experienced orofacial and/or dental pain are related in a bidirectional or cyclical manner.

\section{Fear of Pain is a Critical Component of Dental Care-Related Fear}

Given the potential for pain in dental treatment, several researchers have focused attention on the relations among orofacial pain, fears about pain, and fears about dental treatment, more generally. To be certain, a relatively large body of evidence provides support for a strong association between fear of pain and dental care-related fear. McNeil and Berryman 
(1989) published the first known data suggesting that fear of pain is a key component of dental care-related fear. This finding has been replicated across several clinical and community samples and across age groups (e.g., McNeil et al., 2001; McNeil et al., 2011; McNeil et al., 2013; Randall, McNeil, \& Stuchell, 2012; Randall, et al., 2016b). Relatedly, fear of dental pain, specifically, has been associated with dental care-related fear in several studies (e.g., Binkley et al., 2009; van Wijk \& Hoogstraten, 2003). It appears that fearing nociception associated with dental treatment may predispose or reinforce in patients dental care-related fear $(\mathrm{McNeil} \&$ Randall, 2014).

\section{Understanding Dental Care-Related Fear and Anxiety: Conceptual and Etiological Issues}

Dental care-related fear and anxiety are distinct but related phenomena, with complex etiologies, that are ubiquitous and impact health behavior. As a result of their associations with oral, systemic, and psychological health, and their widespread prevalence, dental care-related fear and anxiety represent public health concerns that warrant scientific and clinical attention. Though complete conceptualizations of these phenomena still are being constructed, much already is understood about the development, maintenance, and implications of them. To begin, dental care-related fear and anxiety, just as with fears and anxieties related to other stimuli, are separate phenomena, even if there is significant overlap (McNeil, Vrana, Melamed, Cuthbert, \& Lang, 1992; Poulton, Waldie, Thomson, \& Locker, 2001). Typically, dental care-related fear describes an individual's physiological, behavioral, and cognitive responses to dental stimuli, almost always occurring in the immediate presence of those stimuli (Craske, 2003; Lang, 1968). Specifically, dental care-related fear often is characterized by physiological responsivity, avoidance behavior, and feelings and verbal report of apprehension or tension, with the physiological component particularly strong (Craske, 2003; McNeil \& Randall, 2014). Dental 
care-related anxiety, on the other hand, describes an emotional response to stimuli related to dental treatment that often occurs prior to and in anticipation of encountering the stimuli. Cognitions, namely negative thoughts and worries, are a key feature of anxiety, often playing much more of a role than in the fear response (Craske, 2003; McNeil \& Randall, 2014). Most "nervous" dental patients experience both dental care-related fear and anxiety. Available psychometrically sound measures of dental care-related fear and anxiety do not make a distinction between the two phenomena; therefore, for the purposes of this study, 'dental carerelated fear' will refer to what likely is both dental care-related fear and/or anxiety.

Though often incorrectly thought of as binary phenomena (i.e., fearful or non-fearful), contemporary conceptualizations of dental care-related fear and anxiety consider their experience as falling somewhere on a continuum (see McNeil \& Randall, 2014). That is, dental care-related fear and anxiety are dimensional, with patients experiencing any of a range of levels of fear or anxiety, from no fear/anxiety at all to "normal" levels of fear/anxiety to significant or even phobic levels of fear/anxiety. At very high or phobic levels, dental care-related fear probably best is conceptualized as Specific Phobia, Situational Type (de Jongh et al., 1998; Leutgeb, Schäfer, \& Schienle, 2011; McNeil \& Randall, 2014). The most recent iteration of the Diagnostic and Statistical Manual for Mental Disorders (5 ${ }^{\text {th }}$ ed.; DSM-5; American Psychiatric Association, 2013) suggests that all instances of dental phobia should be categorized as Blood-Injury-Illness (BII) Phobia; however, given what is known about dental phobia, this categorization is not always appropriate and such a diagnostic strategy therefore may be inaccurate (see McNeil \& Randall, 2014). Of course, in some cases, dental care-related fear can be well understood as a BII Phobia or as an injection phobia (McNeil \& Randall, 2014). Still, it should be reiterated that patients need not experience phobic levels of dental care-related fear in order for the fear to 
manifest in a noteworthy or impactful manner. Individuals along the continuum of dental carerelated fear have a unique and idiosyncratic experience and presentation of fear, or alternatively, comfort, related to dental situations.

Several mechanisms describing the developing and maintaining factors of dental carerelated fear have been posited. Thus, a number of etiological factors can explain dental carerelated fear, with current conceptualizations combining many of the models (see McNeil \& Randall, 2014). First, conditioning models suggest that dental care-related fear develops and is maintained through classical and operant conditioning paradigms. For example, fear of the dental situation may be the result of, and perpetuated by, associations made between dental stimuli (e.g., the sound of a drill) and aversive experiences (e.g., pain, lack of control; Davey, 1989; Kent, 1985). Likewise, dental care-related fear may develop via positive reinforcement when a child displaying fear behavior encounters special attention from the dental professional or a parent, or via negative reinforcement, when fear behavior (e.g., squirming, taking frequent breaks) provides relief from aversive dental stimuli (McNeil \& Randall, 2014). Newer conditioning models have highlighted the role of avoidance in maintaining dental care-related fear. A vicious cycle of dental care-related fear has been described such that a negative dental experience leads to dental care-related fear, which leads to avoidance of dental treatment, and then to dental problems, and thus additional aversive dental experiences, completing the cycle by perpetuating dental care-related fear (see Armfield, Stewart, \& Spencer, 2007).

Second, social learning theory has been applied to dental care-related fear. These conceptualizations of the etiology of fears about dentistry suggest that, through observational or vicarious learning mechanisms, dental patients become fearful, even when they never have experienced painful or negative dental situations, by learning about the (potentially) aversive 
nature of dental procedures from family, friends, or the media (McNeil, Randall et al., 2014; Melamed \& Williamson, 1991; Milgrom et al., 2009).

Third, cognitive models of the acquisition and maintenance of dental care-related fear propose that misperceptions, misattributions, cognitive biases, and negative thinking patterns are critical. Data suggest that misappriasing risk and thinking patterns that involve catastrophizing are important moderators of dental care-related fear (de Jongh, Muris, ter Horst, van Zuuren, \& de Wit, 1994). A cognitive vulnerability model describes dental care-related fear as being the result, at least in part, of maladaptive thinking style and misperceptions about controllability, predictability, dangerousness, and disgustingness (Armfield, 2006; 2010a). Learning history and genetic predispositions related to anxiety likely are important in this cognitive vulnerability (McNeil \& Randall, 2014).

Fourth, models that include personality traits suggest that the etiology of dental carerelated fear involves stable trait anxiety and/or neuroticism, and some data support such models (Thomson, Broadbent, Locker, \& Poulton, 2009; Vassend, Roysamb, \& Nielsen, 2011). Lastly, pain-related factors may be particularly important in understanding the etiology of dental carerelated fear. For instance, heightened pain sensitivity and low pain tolerance/threshold may provide a critical vulnerability for dental care-related fear (Bernstein, Kleinknecht, \& Alexander, 1979; Wardle, 1982). Several studies highlight the importance of pain perception in the experience of dental care-related fear (e.g., Sandikop, Agrawal, \& Patil, 2011; Tickle, Milsom, Crawford, \& Agrawal, 2012; van Wijk \& Makkes, 2008). A comprehensive conceptual model describing dental care-related fear, and incorporating each of these important etiological factors, has been proposed by McNeil and Randall (2014; see Appendix A). That model includes 
biological and genetic factors, which also are theoretically important. Given that these factors are understudied, they are the subject of this project.

\section{Impact of Dental Care-Related Fear}

As noted earlier, dental care-related fear is common, with 45 million adults living in the USA reporting at least moderate levels (Dionne et al., 1998), and similar rates reported in other parts of the world (e.g., Armfield et al., 2006; Domoto et al., 1988; Klinberg, Berggren, \& Noren, 1994; Moore, Birn, Kirkegaard, Brodsgaard \& Scheutz, 1993). The most recent metaanalysis on the topic suggests that between 10 and $20 \%$ of American adults report a high degree of dental care-related fear, a prevalence rate that has remained stable over the last six decades, even though dental treatment has seen vast improvements in quality and comfort (Smith \& Heaton, 2003). Dental phobia, dental care-related fear at the extreme, is the third most prevalent phobia (Oosterink et al., 2009). Clearly, dental care-related fear affects a great number of people. It should be noted, however, that this fear is not distributed evenly across the population. Consistently published is the finding that more women, compared to men, report higher levels of dental care-related fear (e.g., Craske, 2003; Doerr Doerr, Lang, Nyquist, \& Ronis, 1998; Heft, Meng, Bradley, \& Lang, 2007; Liddell \& Locker, 1997); the reasons for this sex difference are not completely known (McNeil \& Randall, 2014). Across ages, there is a bimodal distribution of dental care-related fear in the population, with young adults and middle-aged adults reporting higher levels of fear (Oosterink et al., 2009), and older adults reporting lower levels of fear (Armfield, Spencer, \& Stewart, 2006; Locker \& Liddel, 1991), relative to other age groups. Among other demographic variables, lower socioeconomic status appears to be related to greater levels of dental care-related fear (Armfield et al., 2006; Doerr et al., 1998). 
A defining manifestation of fear is avoidance behavior, and dental care-related fear, not surprisingly, leads to (and is exacerbated by) avoidance of both asymptomatic and symptomatic dental treatment. Specifically, dental care-related fear is negatively associated with frequency of dental check-ups (Doerr et al., 1998), and positively associated with avoidance of dental appointment scheduling (Meng, Heft, Bradley, \& Lang, 2007) and avoidance of dental treatment (Armfield et al., 2007). These associations are demonstrated even when controlling for socioeconomic status and treatment accessibility. Not surprisingly, treatment avoidance is correlated with poorer oral health (e.g., decayed and missing teeth, fewer functional teeth; Schuller et al., 2003). Treatment avoidance has been suggested as serving a mediating role in the predictive positive association between dental care-related fear and number of decayed and missing teeth, and predictive negative association between fear and number of filled teeth, as observed in two large-scale, community-based studies (Armfield, Slade, \& Spencer, 2009; Randall, McNeil, Wiener et al., 2013). In addition to treatment avoidance, dental care-related fear also is negatively associated with oral self-care, such as brushing, flossing, and compliance with treatment regimens (Ojima et al., 2005; Riley, Gilbert, \& Heft, 2006). Taken together, available data provide substantial support that dental care-related fear greatly impacts dental care utilization and associated oral health status.

Poorer oral health associated with dental care-related fear has been tied to several negative psychological outcomes. For example, dental care-related fear and associated oral health outcomes are positively correlated with dissatisfaction with one's mouth (Doerr et al., 1998). Dental care-related fear also is associated with lower quality of life (Crofts-Barnes et al., 2010) and lower self-esteem and morale (Locker, 2003). 
Similarly, a large body of literature has linked poorer oral health with numerous negative systemic health outcomes. For instance, untreated dental disease may exacerbate diabetes and cardiovascular disease (Williams et al., 2008). Epidemiological and laboratory studies suggest that periodontal infections increase the risk for and worsen atherosclerosis and pulmonary infections (Scannapieco \& Genco, 1999). Likewise, periodontal disease has been linked to increased risk for coronary heart disease (Morrison, Ellison, \& Taylor, 1999) and cerebrovascular disease (Wu et al., 2000). Several mechanisms have been proposed to explain the relation between systemic disease and oral infection, such as metastatic spread of infection, metastatic injury by circulating toxins, and metastatic inflammation caused by that injury (Li, Kolltveit, Tronstad, \& Olsen, 2000), and early evidence suggests that the link between dental and systemic diseases is causal in nature (Haumschild \& Haumschild, 2009; Joshipura, Ritchie, Douglass, 2000). Relatedly, untreated dental disease also is associated with worse pregnancy outcomes, possibly the result of infection affecting the unborn fetus (e.g., Gaffield, ColleyGilbert, Malvitz, \& Romaguera, 2001; Offenbacher et al., 1996). Given the far-reaching impact of dental care-related fear, and the high prevalence worldwide, dental care-related fear often is considered a public health concern (McNeil \& Randall, 2014).

\section{Statement of the Problem and Study Aims}

Fear of pain and dental care-related fear both are complex phenomena with multifactorial etiologies across the population (Asmundson et al., 2004; McNeil \& Randall, 2014). As outlined earlier, high levels of general fear of pain are positively associated with pain-related disability, pain intensity, and chronic pain behavior. Similarly negative states associated with dental carerelated fear include avoidance of dental treatment and poorer oral, systemic, and psychological health, among others, as discussed above. Fear of pain appears to be a critical component of 
dental care-related fear (e.g., McNeil \& Berryman, 1989), though also is important in its own right (i.e., in understanding the pain experience across numerous populations and pain conditions). Improving our understanding of fear of pain and fears about dental treatment, both separately and as related constructs, may inform interventions aimed at reducing the burden of these phenomena.

Though much is known about the etiology of both general fear of pain and dental carerelated fear, there is a dearth of literature addressing the role of genetics. A single study has estimated the heritability of fear of pain, with no other known work on the impact of genetic factors on the development and maintenance of the phenotype. In the dental care-related fear literature, only four known studies have sought to elucidate the role of genes in predisposing individuals to clinically significant levels of fear. Nevertheless, biological and genetic variables likely are etiologically important for both fear of pain and dental care-related fear (McNeil \& Randall, 2014). Studies that assess the role of genetics in these phenomena are necessary in order for their conceptualizations to be more comprehensive and complete. An understanding of fear of pain and dental care-related fear that includes genetic variables has the potential to shape personalized interventions that are most efficacious (i.e., personalized medicine and dentistry).

The central goal of the current study was to expand upon the limited genetic knowledge related to fear of pain and dental care-related fear. With regard to the comprehensive conceptual model describing dental care-related fear proposed by McNeil and Randall (2014) and acknowledged earlier, the current study was designed to provide evidence for associations between the components of the model highlighted in Figure 1. Given the theoretically important and previously identified association between dental care-related fear and the $M C 1 R$ gene, the first aim of the study was to determine whether $M C 1 R$ gene variant status predicts dental care- 
related fear, with the expectation of replicating the findings of the Binkely et al. (2009) study. The second aim of the study was to, for the first time, determine whether $M C 1 R$ gene variant status predicts general fear of pain. The third aim of the study was to examine whether fear of pain mediates the association between $M C 1 R$ gene variant status and dental care-related fear. Finally, as a secondary objective, the study explored whether other candidate genes are related to fear of pain and dental care-related fear. The ultimate goal of this project was to contribute to two bodies of literature - fear of pain and dental care-related fear - such that conceptualizations of these public health problems may be refined in ways that can influence the development and implementation of the treatments that target them.

\section{Hypotheses}

First, drawing on previous research (Binkley et al., 2009), it was hypothesized that $M C 1 R$ gene variant status would predict level of dental care-related fear in a large Appalachian community sample of adults (Hypothesis 1). Second, given the relation previously observed between MC1R gene variant status and fear of dental pain (Binkely et al., 2009), and the wellreplicated finding that dental care-related fear and general fear of pain are associated (e.g., McNeil \& Berryman, 1989), it was expected that $M C 1 R$ variant status would predict level of general fear of pain in the same sample (Hypothesis 2). Third, and conditional on results supporting Hypotheses 2 and 3, it was anticipated that the relation between $M C 1 R$ gene variant status and dental care-related fear would be mediated by fear of pain (Hypothesis 3).

\section{Method}

\section{Design}

The current investigation utilized existing data from a large, family-based study of the Center for Oral Health Research in Appalachia, cohort 1 (COHRA1), the same data set from 
which the previously reported heritability estimates for fear of pain and dental care-related fear were calculated (Randall et al., 2016b). The larger, cross-sectional project was initiated to identify in an Appalachian sample determinants of oral diseases at the community-, family-, and individual levels, and data were collected over a seven-year period. A comprehensive protocol included a large battery of self-report measures related to several aspects of oral health (including psychosocial ones), standardized interviews, oral health assessment, microbiological assessment, and DNA collection. The study protocol was developed by a committee with expertise in genetics, microbiology, epidemiology, biostatistics, behavioral science, community assessment, rural health, and dentistry (Polk et al., 2008). A complete description of the study protocol is beyond the scope of this manuscript; it has been described elsewhere (see Marazita et al., 2005; Polk et al., 2008). Methods of self-report data collection for this study have been outlined and critiqued (see Randall, McNeil, Crout et al., 2013). Written informed consent was obtained from adult participants and parents or legal guardians of child participants; verbal assent was obtained from children who could grant assent. The study design and all materials were approved by the Institutional Review Boards of West Virginia University and the University of Pittsburgh.

\section{Participants}

Participants were recruited in Webster and Nicholas counties of West Virginia and Allegheny, Washington, and McKean counties of Pennsylvania. According to the householdbased protocol, eligibility criteria required that households must contain at least one biological parent-child (i.e., age 1 to 18 years) pair. All members of eligible households who volunteered were invited to participate, without regard to biological or legal relationships and without regard to oral health status. Psychosis, neurological impairment, and severe physical or mental disability 
comprised participant exclusion criteria. Households were excluded if at least one member of the biological parent-offspring pair exhibited impaired blood clotting or diminished capacity to resist infection. Given the recruitment strategy, a community-based sample that reflects a range of the Appalachian population was obtained - a notable range in socioeconomic statuses, cultural behaviors, attitudes, and access to oral health care was observed (Polk et al., 2008). Additionally, racial and ethnic composition of this part of the Appalachian region was reflected in the sample (Polk et al., 2008). On the whole, participants in this sample, as compared to the greater USA population, were socioeconomically disadvantaged and suffered from poorer oral health across several indices (e.g., Martin et al., 2008; Shaffer et al., 2012; Wang et al., 2010).

In total, 732 households were enrolled in the COHRA1 study, with 2,663 individuals participating from 740 biological families. For the proposed project, only genotyped participants who completed measures of fear of pain and dental care-related fear were included in analyses (participants age 11 years and older completed such measures). To ensure participant independence, only those who were not genetically related were included in the sample (e.g., included only one member [mother] of a biological mother-child pair); the result was the inclusion of only adults, as children were enrolled in the COHRA1 study as a function of relatedness to at least one enrolled parent and, for the current study, parents were selected for over children in the elimination of genetically related participants. Furthermore, in keeping with human MC1R studies (e.g., Binkely et al., 2009, Liem et al., 2005), and to allow for straightforward comparison, only self-reported Caucasian/white participants were included in final analyses. ${ }^{2}$ Thus, the current study involved the analysis of data for 817 participants. Figure 2 depicts the selection of these participants from the full COHRA1 sample. 


\section{Self-Report Assessment Instruments}

Demographic questionnaire. A questionnaire designed to collect demographic information was developed specifically for the purposes of the COHRA1 study, and variables included are outlined elsewhere (Polk et al., 2008). For the current study, reported age (years), sex, education (years), and socioeconomic status (measured by a validated proxy, the "community ladder" item of the MacArthur Scale of Subjective Social Status; Adler \& Stewart, 2007; See Appendix B) were the demographic variables utilized.

Fear of Pain Questionnaire-9. The Fear of Pain Questionnaire-9 is a self-report measure of fears about pain, generally (FPQ-9; McNeil et al., 2017). The 9-item instrument contains three factor analytically derived subscales: Fear of Severe Pain, Fear of Minor Pain, and Fear of Medical/Dental Pain. Responses are made using a 5-point Likert-type scale; an indication of how fearful the respondent is of the pain associated with each of several painful experiences is provided. The FPQ-9 assesses fears about pain induced by a broad range of stimuli or situations. The instrument is presented in Appendix C. Each subscale contains three items and possible scores range from 3-15; possible total score ranges from 9-45. Higher scores are indicative of greater levels of fear of pain.

The FPQ-9 was developed from the longer Fear of Pain Questionnaire-III (FPQ-III; McNeil \& Rainwater, 1998). The FPQ-III has established norms for clinical (i.e., chronic pain patients, general medical outpatients) and nonclinical populations, and well-evidenced reliability and validity (McNeil \& Rainwater, 1998; Osman, Breitenstein, Barrios, Gutierrez, \& Kopper, 2002; Roelofs et al., 2005). The FPQ-9 retains the factor structure of the FPQ-III (Randall, Waddell et al., 2013) and has similarly strong reliability and validity as the FPQ-III (McNeil et al., 2017). It has been used with success in several studies (e.g., Randall et al. 2012). For its 
strong psychometric properties and utility, and its ability to tap general fear of pain, this instrument is of value for the current study.

Dental Fear Survey. The Dental Fear Survey (DFS) is a 20-item, self-report measure of fearful and anxious reactions to dental stimuli and situations (Kleinknecht, Klepac, \& Alexander, 1973; see Appendix D). The instrument assesses both physiological and behavioral responses to dental situations (e.g., increased heart rate during dental treatment, avoidance of treatment via appointment cancellation). Additionally, the instrument assesses severity of the fear response to various dental stimuli (e.g., the dental chair, the anesthetic needle, the sound of the drill). Using a 5-point Likert-type scale, respondents rate how much each physiological or behavioral response occurs or how much fear/anxiety they experience when presented with fear-inducing dental stimuli. Total sore ranges from 20-100; higher scores indicate greater levels of dental carerelated fear. Three factor analytically derived subscales comprise the DFS: one related to anticipatory anxiety and treatment avoidance, one related to fear of specific stimuli, and the other related to physiological arousal associated with dental treatment/stimuli (Kleinknecht et al., 1973).

The DFS is very widely used in behavioral dentistry research because of its strong psychometric properties. Stability in the factors and scores across time has been observed in both clinical and nonclinical samples (Kleinknecht et al., 1973) and internal consistency and testretest reliability has been confirmed (Kleinknecht, Thorndike, McGlynn, \& Harkavy, 1984; McGlynn, McNeil, Gallagher, \& Vrana, 1987). Predictive, convergent, and discriminant validity also has been observed (Smith \& Moore, 1994; Wilson \& Sinisko, 1997). A critical review of anxiety and pain measures in dentistry resulted in the suggestion that the DFS be used to measure dental care-related fear in research applications involving adults (Newton \& Buck, 2000). Given 
its psychometric properties and comprehensiveness, the DFS is preferable in research settings to other measures of dental care-related fear (Newton \& Buck, 2000), such as Corah's Dental Anxiety Scale (used in the Binkely et al. [2009] study), and as such is utilized in the current study. It should be noted, however, that the DFS, while important historically and currently, has been criticized for not being based on theory. For instance, the DFS utilizes a single summary score without a clear rationale and may be more appropriate for clinical practice than for research (Armfield, 2010b). While other and more recent dental care-related fear self-report assessments exist (e.g., Armfield, 2010b), the DFS has been used extensively (Armfield, 2010a) and continues to have utility, particularly in comparing results in longitudinal investigations and cross-sectionally in comparison to prior studies. Participants of the COHRA1 study completed the DFS and FPQ-9 as part of the larger battery of study questionnaires.

\section{DNA Collection and Available Genetic Data}

During the early part of the COHRA1 study, DNA was collected for all consenting participants from blood samples procured by trained phlebotomists from peripheral veins (Polk et al., 2008). The majority of COHRA1 study participants, however provided saliva or cheek swab samples from which DNA was extracted (Polk et al., 2008). The change in DNA collection method resulted from the availability of improved methodologies, allowing reliable extraction from saliva. Collected DNA was genotyped on an Illumina platform (600,000 SNPs). The genotype data already have been extensively validated, cleaned, quality checked, and formatted for statistical analysis (see Data Cleaning Report; Marazita, 2010).

Though the MCIR gene was not explicitly sequenced for each COHRA1 study participant, 31 SNPs within the MC1R coding region had been genotyped or imputed, and those data were available for the study sample. Each of these SNPs were considered for use in analyses 
for the present study, though only 6 ultimately, were utilized. In determining $M C 1 R$ gene variant status in a similar study, Binkely and colleagues (2009) determined the genotype of each participant at 12 SNPs, and sequenced the entire coding region of the gene for approximately half of their sample. In the end, the authors of that study utilized only eight SNPs to determine $M C 1 R$ variant status, based on results of a study indicating the MC1R SNPs that most likely significantly decrease the function of the gene (Binkely et al., 2009; García-Borrón, SánchezLaorden, \& Jiménez-Cervantes, 2005). To be congruent with the Binkely et al. (2009) study on the relation between $M C 1 R$ gene variants and dental care-related fear, this study involved labeling as variant minor allele(s) the same $\operatorname{SNP}(\mathrm{s})$. The data available for this project included six of the SNPs targeted by Binkely and colleagues (2009), and notably the MC1R SNP most well-known for being related to pain sensitivity and/or decreased anesthetic efficacy (i.e., rs 1805007). The following SNPs were analyzed for the present study: rs1805006, rs11547464, rs 1805007, rs1110400, rs1805008, rs1805009 (labeled using protein product notation in the Binkley et al. [2009] study: D84E, R142H, R151C, I155T, R160W, and D294H, respectively). These SNPs were chosen not only for comparability to the study by Binkley and colleagues (2009), but, like in that study, also based on their likelihood of affecting $M C 1 R$ function. Minor alleles at these six SNPs are missense (coding) variants responsible for amino acid residue changes that are predicted to be deleterious to protein function (García-Borrón et al., 2005). The SNPs are moderate $(<10 \%)$ to low $(<1 \%)$ frequency coding variants and linkage disequilibrium among them is low $\left(r^{2}<0.2\right.$; see Table 1$)$.

\section{Determining $M C 1 R$ Variant Status}

For the proposed project, genetic data were combined across SNPs to calculate a risk score, as was done by Binkely and colleagues (2009). Variant (i.e., minor) alleles were 
determined by referencing SNPedia (http://www.snpedia.com) and GeneCards (http://www.genecards.org) and are reported with study results as consistent with similar literature (e.g., MacQueen et al., 2014). Participants were assigned to one of two groups based on the number of SNPs for which they carry a minor allele: zero target SNPs, or one or more target SNPs. Variant status thus describes whether $M C 1 R$ variations are present. Participants with minor allele(s) at one or more target SNPs were considered to have positive variant status, and participants with no variation at these SNPs were considered to have negative variant status. With regard to determination of $M C 1 R$ variant status, study results do not differ based on method of $M C 1 R$ variant group assignment. For example, very similar (and not statistically different) results are obtained when participants are sorted into the following three groups: participants with zero variant alleles, participants with one variant allele, and participants with two (or more) variant alleles.

\section{Determining MC4R, OPRM1, COMT, and SCN9A Variant Status}

As noted earlier, the $M C 4 R$ gene is potentially functionally related to the $M C 1 R$ gene, though the two are on different chromosomes (i.e., $M C 4 R$ is on chromosome 18). A common $M C 4 R$ SNP (Chowdhury et al., 2013) was selected to be used in analyses for the present study: rs 11872992. Presence of the minor allele was labeled as variant for the study. OPRM1 variation has been associated with pain perception; rs 1799971 (i.e., A118G) is the OPRM1 SNP that has been linked to experimentally-induced pain sensitivity (Fillingim et al., 2005), and for which presence of the minor allele was labeled as variant for these study analyses. With regard to COMT, participants with the minor allele at one or both of two SNPs (rs6269 and rs4818) were labeled as variant. These SNPs are highly predictive of the role of COMT in temporomandibular joint disorder (TMD; Diatchenko et al., 2005). Lastly, and similarly, participants with the minor 
allele at one or both of two SNPs (rs6746030 and 41268673) on SCN9A, which have been associated with pain disorders (e.g., Reimann et al., 2010), were labeled as variant.

\section{Statistical Analyses}

Following determination of $M C 1 R$ variant status for all participants, demographic, fear of pain, and dental care-related fear data were merged with genetic data, and quality of the data merging process was checked. Missing data for demographic variables were accounted for using regression imputation; 1 participant was missing age data, 10 participants were missing education data, and 21 participants were missing subjective social status data. The same process was utilized to account for missing FPQ-9 and DFS data, as outlined by Randall and colleagues (2013). There were no missing genetic data for the study sample. As is recommended in the literature (Tabachnick \& Fidell, 2007), univariate outliers were screened for by considering standardized scores; none were found. All statistical analyses were performed using SPSS Statistics 21 (IBM SPSS, Chicago, IL) and the PROCESS macro (Hayes, 2013) for SPSS Statistics. Effect size calculations (i.e., Cohen's $d$ ) for $t$-tests were conducted using Effect Size Calculators (Becker, 1999).

\section{Results}

\section{Sample Characteristics, Fear of Pain, and Dental Care-Related Fear}

First, descriptive statistics (e.g., means and standard deviations) were calculated, and bivariate correlational analyses were employed to determine the relation between fear of pain, dental care-related fear, age, education, and socioeconomic status for the total sample. The sample of 817 participants comprised 511 females $(62.5 \%)$, and mean age was 34.7 years $(S D=$ 8.7 , range $=18-67)$. Participants had, on average, 13.1 years of education $(S D=2.5$, range $=4$ - 
23). The average response on the "community ladder" item of the MacArthur Scale of Subjective Social Status was $5.7(S D=2.0$, range $=1-10)$.

Mean FPQ-9 score was $23.2(S D=8.1$. range $=9-45)$ and mean DFS score was $39.2(S D$ $=19.2$, range $=20-100)$. Mean subscale scores for both measures are listed in Table 2. Average FPQ-9 and DFS scores were consistent with those observed in studies of similar populations (e.g., Randall et al., 2012). As has been previously reported for this sample (Randall et al., 2016b), distributions of FPQ-9 and DFS matched existing research: negatively skewed, with nearly $15 \%$ of participants reporting extremely high levels of fear of pain and/or phobic levels of dental care-related fear. Bivariate correlations between demographic variables and FPQ-9 and DFS scores are listed in Table 3.

Basic between-group comparisons (i.e., $t$-tests) were utilized to determine whether there are differences in general fear of pain and dental care-related fear between males and females for the total sample. Females reported higher (FPQ-9 $M=24.6, S D=7.9$ ) and males reported lower (FPQ-9 $M=21.2, S D=7.8$ ) levels of fear of pain, $t(815)=5.9, p<0.001$, Cohen's $d=.41$.

Likewise, females reported higher (DFS $M=40.3, S D=19.6$ ) and males reported lower (DFS $M$ $=37.5, S D=18.2)$ levels of dental care-related fear, $t(815)=2.0, p=.04$, Cohen's $d=.14$. This sex difference, of small effect size, has been widely observed, specifically in dental care-related fear, and across many fears (see Craske, 2003; McNeil \& Randall, 2014). Demographic data and FPQ-9 and DFS subscale data, divided by sex, are reported in Table 4. Age and subjective social status were not significantly associated with FPQ-9 or DFS scores; education was not significantly associated with FPQ-9 score and was significantly, but only weakly, associated with DFS score (see Table 3). In light of these findings, sex, but not other demographic variables, was controlled for in subsequent analyses. 


\section{MC1R Variation}

In total, 546 participants had no $M C 1 R$ risk variants, 249 had one risk variant, and 22 had two risk variants; no participant had more than two variants. Thus, 271 participants (33.2\%) had at least one risk allele, a proportion consistent with that observed in the dark-haired Caucasian (i.e., not redhead) subsample of the only other similar study (Binkely et al. 2009). Table 5 summarizes the proportion of the sample with $M C 1 R$ risk alleles for each of the study SNPs, and notes minor allele for each of the SNPs.

Basic between-group comparisons (i.e., chi-square, $t$-tests) were utilized to determine whether there were sex, age, education, or socioeconomic differences between positive and negative $M C 1 R$ variant status. Given that there exist potential sex differences in the heritability of dental care-related fear (Ray et al., 2010) and that the influence of $M C 1 R$ on pain perception may be sex-specific (Delaney et al., 2010), it was imperative to test the effect of sex on $M C 1 R$ variant status. In this sample, females and males did not differ in their likelihood of having one or more $M C 1 R$ risk alleles, $X^{2}(2, \mathrm{~N}=817)=1.86, p=.17(160$ of 511 females and 110 of 306 males in the sample had one or more $M C 1 R$ variant). Similarly, presence of risk alleles at one or more $M C 1 R$ SNPs was not associated with age, $t(815)=1.4, p=.15$, education, $t(815)=.25, p=$ .80 , nor subjective social status, $t(815)=1.23, p=.22$.

\section{MC1R Variation, Fear of Pain, and Dental Care-Related Fear}

To address Hypotheses 1 and 2, that $M C 1 R$ gene variant status predicts dental carerelated fear and fear of pain, respectively, multiple linear regression analyses were utilized. An additive hierarchical regression was conducted with $M C 1 R$ gene variant status as the independent variable and either dental care-related fear or fear of pain as the dependent variable, controlling for covariates (i.e., sex). There were no issues with muticollinearity. 
$M C 1 R$ variant status was predictive of dental care-related fear, $F(2,814)=4.20, p=.02$, $R^{2}=.01$, controlling for sex. Likewise, $M C 1 R$ variant status was predictive of general fear of pain, $F(2,814)=21.08, p<.001, R^{2}=.05$, controlling for sex. Presence of one or more $M C 1 R$ variant(s) was associated with increased DFS and FPQ-9 scores. See Table 6 for results of regression analyses.

The $M C 1 R$ variant status scoring scheme used in this study (i.e., calculating a risk score by determining whether participants had variation at either none or one or more of six SNPs, as in Binkely et al. [2009]) may mask the reporting of individual SNPs and the association among genetic variation and phenotype. Thus, the association of variation at each of the study SNPs with DFS and FPQ-9 scores was investigated independently by SNP. Those results are presented in Table 7. For only one SNP, rs1805007, presence of the minor allele significantly predicted DFS and FPQ-9 scores. The other SNPs were not significantly related to either dental carerelated fear nor fear of pain and showed large standard errors of their effect estimates, indicating insufficient power to precisely model their effects. Additionally, variation at four of the six SNPs is relatively rare in this sample. As such, study results appear to be driven predominantly by variation at rs 1805007.

To address Hypothesis 3, that fear of pain mediates the relation between $M C 1 R$ variant status and dental care-related fear, mediation was tested using the PROCESS macro (Hayes, 2013) for SPSS Statistics. Relative indirect effects were subjected to post hoc bootstrap analyses with 5000 samples and a 95-percentile confidence interval estimate. PROCESS allows for dichotomous independent variables in mediational analyses as well as analysis of data that are not normally distributed (as in the case of the DFS and FPQ-9 data in the current study), and is 
the contemporary strategy of choice for determining mediation effects in research with psychological phenomena.

FPQ-9 and DFS scores were moderately correlated $(r=.50, p<.001)$. Given, this association, and the well-supported suggestion that fear of pain is a primary component of dental care-related fear (McNeil \& Berryman 1989), a single mediator model was tested with fear of pain (FPQ-9 score) as the mediating variable to explain the association between $M C 1 R$ variant status and dental care-related fear (DFS score); see Table 8 and Figure 3. Full mediation was observed. There was a significant indirect effect of $M C 1 R$ variant status on dental care-related fear through fear of pain, $\mathrm{B}=1.60, \mathrm{BCa} \mathrm{CI}[0.281,3.051]$. The size of this effect was small to moderate, $\mathrm{K}^{2}=.044,95 \% \mathrm{BCa}$ CI $[.009, .082]$.

\section{Exploratory Analyses}

To complete the secondary and exploratory objective of this study, the same general statistical approach as was used for the $M C 1 R$ data was used to determine whether variants of the $M C 4 R, O P R M 1, C O M T$ and SCN9A genes were associated with fear of pain and/or dental carerelated fear, given the literature summarized earlier.

MC4R. Of 817 participants, 207 (25.3\%) had risk a risk allele at the MC4R SNP genotyped for this study (rs11872992). MC4R variation was not associated with $M C 1 R$ variation, $X^{2}(2, \mathrm{~N}=817)=.86, p=.36$. Controlling for sex, $M C 4 R$ variation was predictive of lower DFS score (for participants with the $M C 4 R$ risk allele, DFS $M=36.8, S D=18.4$; for participants without $M C 4 R$ risk allele, DFS $M=40.1, S D=19.4), F(2,814)=4.04, p=.02, R^{2}=.01$. Results of the regression model used to test this association are presented in Table 9. There was no difference in FPQ-9 score between participants with and without $M C 4 R$ variation, $t(815)=1.8, p$ 
$=.07$. Given that there was no significant relation between $M C 4 R$ variant status and fear of pain, follow-up mediational analysis was not warranted.

OPRM1, COMT, and SCN9A. In this sample, 181 (22.2\%) participants had the risk allele for the OPRM1 SNP analyzed. Variance on the OPRM1 gene was associated with neither FPQ-9 score, $t(815)=.06, p=.96$, nor DFS score, $t(815)=.78, p=.43$. The prevalence of participants with risk allele(s) at one or both of the COMT SNPs analyzed for this study was $62.2 \%(n=508) . C O M T$ variance was not associated with FPQ-9 score, $t(815)=.62, p=.54$, nor DFS score, $t(815)=.41, p=.68$. Approximately one-third $(31.7 \% ; n=259)$ of the participants had risk allele(s) at one or both of the $S C N 9 A$ SNPs analyzed for the study. SCN9A variance had no association with FPQ-9 score, $t(815)=.45, p=.65$, nor DFS score, $t(815)=.26, p=.80$.

\section{Discussion}

As expected, $M C 1 R$ variant status is associated with dental care-related fear. Participants with one or more risk alleles in the $M C 1 R$ coding region were more likely than those with none to report greater levels of dental care-related fear on the DFS, supporting Hypothesis 1. MC1R variant status also is associated with general fear of pain. In support of Hypothesis 2, participants with one or more variants in the $M C 1 R$ coding region were more likely than those with none to report greater levels of fear of pain, as measured by the FPQ-9. Perhaps most fascinating - and important - is the finding that the relation between $M C 1 R$ variant status and DFS score is explained by FPQ-9 score. That is, fear of pain fully mediates the relation between $M C 1 R$ variant status and dental care-related fear, providing support for Hypothesis 3. Interestingly, variation at one study SNP, rs1805007, appears to drive these observed associations.

Critically, these findings extend those of the few other studies on the topic of genetic contributions to dental care-related fear. As mentioned earlier, three studies have demonstrated 
moderate to high heritability for dental care-related fear (30-47\%; Randall et al., 2016b; Ray et al., 2010; Vassend et al., 2011). And, as highlighted previously, Binkely and colleagues (2009) determined that $M C 1 R$ variant status (i.e., having one or more gene variants versus no variants) predicts greater fear of dental pain and dental care-related fear, as well as a two-fold increase in the likelihood of avoiding dental care. Results of the current study provide the first known confirmation of the primary findings reported by Binkley and others (2009), replicating the result of the only other known study on the topic. Taken together, it is clear that the experience of dental care-related fear is influenced by genetic factors. Moreover, the $M C 1 R$ gene appears to be linked to dental care-related fear, and may be especially important in the development and maintenance of dental care-related fear for some people.

If the literature on the etiology of dental care-related fear is scant with data informing our understanding of genetic contributions, then the same can be said about the fear of pain literature. Notably, only one study has addressed the heritability of general fear of pain, demonstrating a moderate degree (i.e., 34\%) in a community sample of adolescents and adults, the same sample from which the current data are drawn (Randall et al., 2016b). Only two other studies provide evidence for potential genetic contributions to the experience of fear of pain. First, the same study that demonstrated a link between $M C 1 R$ variation and dental care-related fear (Binkley et al., 2009) also showed that $M C 1 R$ risk alleles are predictive of fear of dental pain, a distinct from, though partially overlapping, general fear of pain (van Wijk, McNeil, Ho, Buchanan, \& Hoogstraten, 2006). Second, the 5-hydroxytryptamine (serotonin) receptor 3B gene $(H T R 3 B)$ has been associated with pain catastrophizing, a phenomenon that overlaps partially with fear of pain (Horjales-Araujo et al., 2013). There is a budding literature on how genetic variation may play a role in the development and manifestation of fear of pain, and this study 
contributes to that literature. The present study offers evidence that there are genetic influences in the experience of fear of pain, and is the first to implicate $M C 1 R$ variation as a contributor to general fear of pain.

Building on existing work summarized here, this study demonstrates that the association between $M C 1 R$ risk alleles and dental care-related fear is through an association between $M C 1 R$ variation and fear of pain, and is the first to do so. By extension, this finding offers preliminary biological support for the well-documented notion that fear of pain is a primary component of dental care-related fear (McNeil \& Berryman, 1989). Equally or perhaps even more interesting, results of the current study suggest that the role of genetic factors in the development and maintenance of dental care-related fear may be through pain-related phenomena. That fear of pain is the mediating variable in the association between $M C 1 R$ variant status and dental carerelated fear suggests that genetically-influenced differences in pain experience (e.g., pain threshold, tolerance) are potential cause for fear of pain, which may then underpin dental carerelated fear.

As observed in a number of studies, $M C 1 R$ variation is associated with heightened sensitivity to pain, including dental pain specifically (e.g., Delaney et al., 2010; Liem et al., 2005; Mogil et al., 2005). The experience of acute and chronic pain can trigger and/or exacerbate fear of pain, which in turn can influence pain perception and pain behavior. For instance, those who have experienced acute and/or chronic orofacial pain are more likely than those who have not to later report fear of pain (van Wijk \& Hoogstraten 2005). And, those with higher levels of fear of pain are more likely to perceive pain stimuli as more intense (van Wijk \& Hoogstraten 2009), to engage in pain catastrophizing (Parr et al. 2012), and to engage in avoidance behaviors that worsen the pain experience (Lee et al. 2007). Of course, and as was replicated in the current 
study, fear of pain is moderately to strongly correlated with dental care-related fear, which is predictive of dental treatment avoidance (e.g., Armfield et al., 2007; Doerr et al., 1998).

Conceivably, then, $M C 1 R$ risk alleles may predispose some people to be more sensitive to pain than others, leading them to have more negative (i.e., painful) experiences with dental treatment. This, in turn, may make those individuals more likely to develop fears about pain and associated fears about dental treatment, and, ultimately, to avoid dental treatment with greater frequency.

\section{Comment on Results of Exploratory Analyses}

Given existing literature, it was expected that variation in genes in addition to $M C 1 R$ would be associated with fear of pain and/or dental care-related fear, and so it was surprising that none of the exploratory analyses afforded meaningfully significant results. For the exploratory analyses, $M C 4 R$ was chosen as a candidate gene because of its known association with anxiety behavior (Chaki \& Okuyama, 2005). Similarly, OPRM1, COMT, and SCN9A were chosen as candidate genes for exploratory analyses for their known associations, generally, with pain sensitivity and pain perception (e.g., Andersen \& Skorpen, 2009; Drenth \& Waxman, 2009; Fillingim et al., 2005). COMT, for example, has even been implicated as important in influencing the orofacial pain experience, as COMT variation is associated with chronic TMD (e.g., Smith et al., 2011).

$M C 4 R$ was the only candidate gene associated with dental care-related fear, and neither $M C 4 R$ nor the other candidate genes included in the exploratory analyses were associated with fear of pain. It is difficult to offer conjecture on these negative results. However, it may be the case that variation in these genes is not associated with dental pain sensitivity, and that the genetic influence on dental pain sensitivity, specifically, is important in any relation between gene variation and dental care-related fear. Though the SNPs analyzed for each of these genes 
were chosen for their documented associations with pain sensitivity and/or other pain-related phenomena, it also may be the case that other SNPs on these candidate genes would have served as better markers of relations between genes and fear of pain and/or dental care-related fear, should such relations exist. Lastly, it may be the case that the study sample was not large and/or diverse enough to detect associations between the candidate genes and fear of pain and/or dental care-related fear. Future work on influence of genetic factors on dental pain, fear of pain, and dental care-related fear should include these genes in order to further establish their role (or nonrole) in those phenotypes.

\section{Implications of the Study}

Generally, the results of this study strengthen the conceptualization of dental care-related fear in that they confirm an etiological role of genetics. Moreover, the results provide additional evidence for a pain-related genetic contribution to the etiology of dental care-related fear. Importantly, the critical roles of pain and fear of pain are underscored by the study findings. Dental care-related fear, with fear of pain as its primary component, most certainly impacts the orofacial pain experience, and is impacted by the orofacial pain experience. The bidirectional influence of orofacial pain on dental care-related fear is well documented, as described above. In worst case scenarios, patients can become caught in a "vicious cycle" of dental care-related fear. In such cases, patients have a painful dental experience, subsequently develop dental care-related fear as a result of aversive conditioning, then avoid necessary dental treatment due to fear, only to have the fear perpetuated when they finally must seek dental treatment that inevitably is especially painful due to neglect (and would otherwise not have been painful if they had not engaged in fear-related avoidance; see Armfield et al., 2007). If patients are genetically 
predisposed to be hypersensitive to orofacial pain (perhaps through $M C 1 R$ gene variation), it follows that they are more likely to end up in such a cycle.

In addition to operating through pain-related mechanisms, there may be a small but potentially important involvement of genetics in dental care-related fear through influence on other important psychological variables. For example, genetic variability may influence basic learning (e.g., conditioning, sensitization, desensitization) in ways that promotes or buffers development/maintenance of dental care-related fear. Because the systemic, oral, and psychological health burdens of dental care-related fear are so profound, a complete conceptualization of the phenomenon is essential. Drawing on the results of this study, future research in the areas of fear of pain and dental care-related fear should incorporate genetic variables, including $M C 1 R$, whenever possible, in order to elucidate their most comprehensive conceptualizations.

From a clinical standpoint, and at the most basic level, results from this study suggest that targeting fear of pain may promote successful amelioration of dental care-related fear. In addition, attending to the idiographic pain experiences of patients may be useful in the treatment of fear of pain and/or dental care-related fear. This study demonstrates promise in the utilization of biomarkers to inform dental treatment planning. Given study results, it may be that knowledge of a patient's $M C 1 R$ status could allow his/her dental care provider to tailor treatment so as buffer the patient from increased risk of fear of pain and dental care-related fear, a la personalized medicine/dentistry. For the practicing dental professional, for example and hypothetically, this may take the form of screening patients for $M C 1 R$ variation early in life, and adapting dental treatment protocol to ensure that those with variants receive particularly comfortable care to reduce their likelihood of experiencing aversive or traumatic dental treatment 
and, ultimately, to reduce their likelihood of developing fear of pain and/or dental care-related fear. Such a recommendation is, of course, premature at this point. Additional research is necessary to uncover the mechanisms by which $M C 1 R$ variation is related to fear of pain and the critical biological pathways involved. Additional research also is necessary to determine the most efficacious ways to utilize knowledge of $M C 1 R$ variant status to inform clinical practice, both for the dental clinician, who may be concerned with pain and fear management, and the mental health clinician, who may be concerned with the treatment of already-developed fears about pain and/or dentistry.

\section{Limitations}

Study limitations include, first, that as a function of utilizing archival data from a larger project aimed at addressing oral health in Appalachia, the sample is geographically and culturally restricted and results may not be generalizable. Replication with samples from other areas is necessary. Moreover, this study and the only other one suggesting a link between $M C 1 R$ and dental care-related fear, analyzed data for only Caucasian/white participants. To more thoroughly and accurately understand the role of $M C 1 R$ variation in the experience of dental care-related fear, and to simultaneously offer a more nuanced understanding of that association and improve generalizability, the same analyses must be completed with members of other ethnic/racial groups. Additionally, self-reported ethnicity/race was used to select cases for study analyses and so may not match genetic ancestry. Future studies should verify participant ethnicity using genotype data and, for samples that include multiple ethnicities, analyses should be stratified by ethnicity/race or adjusted for using principal components of ancestry.

A second limitation of this study is the reliance of self-report instruments to measure the phenotypes of interest. While the questionnaires utilized are psychometrically strong, multimodal 
and behavioral assessment of fear of pain and dental care-related fear would strengthen future study design. Third, no measure of dental treatment-seeking behavior (e.g., time since last dental visit) was utilized. Dental care-related fear certainly is an important phenotype in its own right; however, whether a patient's dental treatment-seeking behavior is reduced due to fear is ultimately most important. Those data were not available for the current study, but should be included in future work on the topic. It also may be helpful to include as a study variable (and control for) history of dental trauma, including previous experiences of particularly painful dental treatment. Such data, and no good proxy for such a variable, was available for the current sample. Lastly, available data are cross sectional, which limits conclusions that can be drawn from mediational analyses. Longitudinal data may allow for stronger claims to be made about the causal relations between genetic variation, fear of pain, dental care-related fear, and dental treatment-seeking behavior.

\section{Directions for Future Research}

Future research should utilize experimental measures of the orofacial pain experience (e.g., quantitative sensory testing) to determine how $M C 1 R$ and other gene variants are related specifically to orofacial pain perception and to clarify whether orofacial pain sensitivity bridges the path between $M C 1 R$ variant status and fear of pain (and associated dental care-related fear). Given the results of the current study, and those that demonstrate that $M C 1 R$ may be important for sensitivity to pain, such an exploration is warranted. Follow-up studies also should test whether $M C 1 R$ variation is related to orofacial pain sensitivity, specifically, or general pain sensitivity (and, similarly, whether $M C 1 R$ variation is related to dental care-related fear, specifically, or fear of medical and other healthcare procedures, broadly). Moreover, there should be studies that address how $M C 1 R$ SNPs affect protein expression and function, and associated 
downstream effects, so that the mechanism(s) by which gene variation is associated with fear of pain and dental care-related fear can be elucidated. Studies that expand understanding of the specific role(s) of genes like $M C 1 R$ may provide additional avenues by which to target pain hypersensitivity and fear of pain that can contribute to dental care-related fear. Gene-byenvironment studies of the influence of genetics on pain perception, fear of pain, and/or dental care-related fear also may be warranted, particularly given the theoretical understanding of the relations between these constructs and their impact on dental treatment-seeking patterns as posited by McNeil and Randall (2014).

The regression models presented here, linking $M C 1 R$ variation, fear of pain, and dental care-related fear, account for only a small proportion of the variance in fear of pain and dental care-related fear (i.e., 1-5\%). As noted earlier, heritability of fear of pain and dental care-related fear is moderate to high (Randall et al., 2016b). Thus, it is likely that there are genes in addition to $M C 1 R$ that may influence fear of pain and dental care-related fear through involvement in pain and/or anxiety pathways or by other means. Future work in the area of genetic influences on fear of pain and dental care-related fear should include genes other than those that were the focus of this study so as to provide an even more comprehensive picture.

\section{Summary}

To conclude, this study corroborates previous work suggesting that $M C 1 R$ variants are associated with dental care-related fear. The study is the first to show that $M C 1 R$ variant status predicts general fear of pain. And, most importantly, results presented here indicate that fear of pain plays a mediational role in the association between $M C 1 R$ variant status and dental carerelated fear. Critically, it is clear that genetic variation contributes to the etiology of dental carerelated fear. This study demonstrates promise in the potential further identification of biomarkers 
that may be useful in determining and personalizing dental treatment. Moreover, these results have important implications for how we understand psychosocial correlates of orofacial pain and dental treatment-seeking behavior, and provide possible specific targets for the treatment of orofacial pain, fear of pain, and/or dental care-related fear. 


\section{References}

Adan, R. A. H., Szklarczyk, A. W., Oosterom, J., Brakkee, J. H. Nijenhuis, W. A. J., Schaaper, W. M. M., ... Gispen, W. H. (1999). Characterization of melanocortin receptor ligands on cloned brain melanocortin receptors and on grooming behavior in the rat. European Journal of Pharmacology, 378, 249-258.

Adler, N., \& Stewart, J. (2007). The MacArthur Scale of Subjective Social Status. Retrieved from: http://www.macses.ucsf.edu/research/psychosocial/subjective.php

American Psychiatric Association. (2013). Diagnostic and statistical manual of mental disorders (5th ed.). Arlington, VA: American Psychiatric Association.

Andersen, S., \& Skorpen, F. (2009). Variation in the COMT gene: Implications for pain perception and pain treatment. Pharmacogenetics, 10, 669-684.

Andresen, T., Lunden, D., Drewes, A. M., \& Arendt-Nielsen, L. (2011). Pain sensitivity and experimentally induced sensitisation in read haired females. Scandinavian Journal of Pain, 2, 3-6.

Armfield, J. (2006). Cognitive vulnerability: A model of the etiology of fear. Clinical Psychology Review, 26, 746-768.

Armfield, J. (2010a). Towards a better understanding of dental anxiety and fear: Cognition vs. experiences. European Journal of Oral Sciences, 118, 259-264.

Armfield, J. M. (2010b). How do we measure dental fear and what are we measuring anyway? Oral Health and Preventive Dentistry, 8, 107-115.

Armfield, J. M. (2010c). Development and psychometric evaluation of the Index of Dental Anxiety and Fear (IDAF-4C+). Psychological Assessment, 22, 279-287. 
Armfield, J. M., Slade, G. D., \& Spencer, A. J. (2008). Cognitive vulnerability and dental fear. BMC Oral Health, 8, 2.

Armfield, J. M., Spencer, A. J., \& Stewart, J. F. (2006). Dental fear in Australia: Who's afraid of the dentist? Australian Dental Journal, 51, 78-85.

Armfield, J., Stewart, J. F., \& Spencer, J. A. (2007). The vicious cycle of dental fear: Exploring the interplay between oral health, service utilization and dental fear. BMC Oral Health, 7, 1-15.

Asmundson, G. J. G., Kuperos, J. L., \& Norton, G. R. (1997). Do patients with chronic pain selectively attend to pain-related information?: Preliminary evidence for the mediating role of fear. Pain, 72, 27-32.

Asmundson, G. J. G., Norton, P. J., \& Veloso, F. (1999). Anxiety sensitivity and fear of pain in patients with recurring headaches. Behaviour Research and Therapy, 37, 703-713.

Asmundson, G. J. G., Norton, P. J., \& Vlaeyen, J. W. S. (2004). Fear-avoidance models of chronic pain: An overview. In G. J. G. Asmunson, J. W. S. Vlaeyen, \& G. Crombez (Eds.), Understanding and treating fear of pain (pp. 3-24). New York: Oxford University Press.

Asmundson, G. J. G., Vlaeyen, J. W. S., \& Crombez, G. (2004). Understanding and treating fear of pain. New York: Oxford University Press.

Becker, L. E. (1999). Effect Size Calculators. Retrieved from: http://www.uccs.edu/ faculty/lbecker/

Beltramo, M., Campanella, M., Tarozzo, G., Fredduzzi, S., Corradini, L., Forlani, A., ... Reggiani, A. (2003). Gene expression profiling of melanocortin system in neuropathic rats supports a role in nociception. Molecular Brain Research, 118, 111-118. 
Bernstein, D. A., Kleinknecht, R. A., \& Alexander, L. D. (1979). Antecedents of dental fear. Journal of Public Health Dentistry, 39, 113-124.

Binkely, C. J., Beacham, A., Neace, W., Gregg, R. G., Liem, E. B., \& Sessler, D. I. (2009). Genetic variations associated with red hair color and fear of dental pain, anxiety regarding dental care and avoidance of dental care. Journal of the American Dental Association, 140, 896-905.

Buer, N., \& Linton, S.J. (2002). Fear-avoidance beliefs and catastrophizing: Occurrence and risk factor in back pain and ADL in the general population. Pain, 99, 485-491.

Ceriani, G., Macalu, A., Catania, A., \& Lipton, J. M. (1994). Central neurogenic antiinflammatory action of $\alpha$-MSH. Neuroendocrinology, 59, 138-143.

Chaki, S., \& Okuyama, S. (2005). Involvement of melanocortin-4 receptor in anxiety and depression. Peptides, 26, 1952-1964.

Chowdhury, N. I., Tiwari, A. K., Souza, R. P., Zai, C. C., Shaikh, S. A., Chen, S., .. Muller, D. J. (2013). Genetic association study between antipsychotic-induced weight gain and the melanocortin-4 receptor gene. The Pharmacogenomics Journal, 13, 272-279.

Conant, E. (2014, June). Feeling red. National Geographic, 225, 17.

Cragnolini, A. B., Schiöth, H. B., \& Scimonelli, T. N. (2006). Anxiety-like behavior inducued by IL-1beta is modulated by alpha-MSH through central melanocortin-4 receptors. Peptides, 27, 1451-1456.

Craske, M. G. (2003). Origins of phobias and anxiety disorders: Why more women than men? Oxford, UK: Elsevier Ltd.

Crofts-Barnes, N., Brough, K., Beddis, A., \& Girdler, N. (2010). Anxiety and quality of life in phobic dental patients. Journal of Dental Research, 89, 302-306. 
Crombez, G., Vlaeyen, J.W., Heuts, P.H., \& Lysens, R. (1999). Pain-related fear is more disabling than pain itself: Evidence on the role of pain-related fear in chronic back pain disability. Pain, 80, 329-339.

Davey, G. (1989). Dental phobias and anxieties: Evidence for conditioning processes in the acquisition and modulation of a learned fear. Behavior Research and Therapy, 27, 51-58.

de Jongh, A., Bongaarts, G., Vermeule, I., Visser, K., De Vos, P., \& Makkes, P. (1998). Bloodinjury-injection phobia and dental phobia. Behaviour Research and Therapy, 36, 971982.

de Jongh, A., Muris, P., ter Horst, G., van Zuuren, F., \& de Wit, C. (1994). Cognitive correlates of dental anxiety. Journal of Dental Research, 73, 561-566.

de Leeuw, R. (2008). American Academy of Orofacial Pain guidelines for assessment, diagnosis, and management (4th ed.). Chicago: Quintessence Publishing Co.

de Wied, D., \& Jolles, J. (1982). Neuropeptides derived from pro-opiocortin: Behavioral, physiological, and neurochemical effects. Physiological Review, 62, 976-1059.

Delaney, A., Keighren, M., Fleetwood-Walker, S. M., \& Jackson, I. J. (2010). Involvement of the melanocortin-1 receptor in acute pain and pain of inflammatory but not neuropathic origin. PLOS ONE, 5, e12498.

Diatchenko, L., Slade, G. D., Nackley, A. G., Bhalang, K., Sigurdsson, A., Belfer, I., ...Shagin, D. (2005). Genetic basis for individual variations in pain perception and the development of a chronic pain condition. Human Molecular Genetics, 14, 135-143.

Dionne, R. A., Gordon, S. M., McCullagh, L. M., \& Phero, J. C. (1998). Assessing the need for anesthesia and sedation in the general population. Journal of the American Dental Association, 129, 167-173. 
Distel, M. A., Vink, J. M., Willemsen, G., Middeldorp, C. M., Merckelbach, H. L. G. J., \& Boomsma, D. I. (2008). Heritability of self-reported phobic fear. Behavioral Genetics, $38,24-33$.

Doerr, P. A., Lang, W. P., Nyquist, L. V., \& Ronis, D. L. (1998). Factors associated with dental anxiety. Journal of the American Dental Association, 129, 1111-1119.

Domoto, P. K., Weinstein, P., Melnick, S., Ohmura, M., Uchida, H., Ohmachi, K., ... Shimono, T. (1988). Results of a dental fear survey in Japan: Implications for dental public health in Asia. Community Dentistry and Oral Epidemiology, 16, 199-201.

Drenth, J. P. H., \& Waxman, S. G. (2007). Mutations in sodium-channel gene SCN9A cause a spectrum of human genetic pain disorders. Journal of Clinical Investigation, 117, 36033609.

Farmer, A., Eley, T. C., \& McGuffin, P. (2005). Current strategies for investigating the genetic and environmental risk factors for affective disorders. British Journal of Psychiatry, 186, $179-181$.

Feldner, M. T., \& Hekmat, H. (2001). Perceived control over anxiety-related events as a predictor of pain behaviors in a cold pressor task. Journal of Behavior Therapy and Experimental Psychiatry, 32, 191-202.

Fillingim, R. B. (2000). Sex, gender, and pain: Women and men really are different. Current Review of Pain, 4, 24-30.

Fillingim, R. B., Kaplan, L., Staud, R., Ness, T. J., Glover, T. L., Campbell, C. M., ... Wallace, M. R. (2005). The A118G single nucleotide polymorphism of the $\mu$-opioid receptor gene (OPRM1) is associated with pressure pain sensitivity in humans. Journal of Pain, 6, 159167. 
Fillingim, R. B., Keefe, F. J., Light, K. C., Booker, D. K., \& Maixner, W. (1996). The influence of gender and psychological factors on pain perception. Journal of Gender, Culture, and Health, 1, 21-36.

Fillingim, R. B., King, C. D., Ribeiro-Dasilva, M. C., Rahim-Williams, B., \& Riley, J. L. (2009). Sex, gender, and pain: A review of recent clinical and experimental findings. Journal of Pain, 10, 447-85.

Flaherty, J. (2010, Spring). Red hot: Your hair color highlights your sensitivity to pain. Magazine of the Tufts University Dental Alumni Association, 14, 4.

Fried, K., Sessle, B. J., \& Devor, M. (2011). The paradox of pain from tooth pulp: Low-threshold “algoneurons"? Pain, 152, 2685-2689.

Gaffield, M. L., Colley-Gilbert, B. J., Malvitz, D. M., \& Romaguera, R. (2001). Oral health during pregnancy: An analysis of information collected by the pregnancy risk assessment monitoring system. Journal of the American Dental Association, 132, 1009-1016.

García-Borrón, J. C., Sánchez-Laorden, B. L., \& Jiménez-Cervantes, C. (2005). Melanocortin-1 receptor structure and functional regulation. Pigment Cell and Melanoma Research, 18, 393-410.

Geer, J. H., \& Davison, G. C. (1970). Reduction of stress in humans through nonveridical perceived control of aversive stimulation. Journal of Personality and Social Psychology, $16,731-738$.

Geisser, M. E., Robinson, M. E., Keefe, F. J., \& Weiner, M. L. (1994). Catastrophizing, depression and the sensory, affective and evaluative aspects of chronic pain. Pain, 59, 7983. 
George, S.Z., Dannecker, E.A., \& Robinson, M.E. (2006). Fear of pain, not pain catastrophizing, predicts acute pain intensity, but neither factor predicts tolerance or blood pressure reactivity: An experimental investigation in pain-free individuals. European Journal of Pain, 10, 457-465.

George, S. Z., Fritz, J. M., \& McNeil, D. W. (2006). Fear-avoidance beliefs as measured by the Fear-Avoidance Beliefs Questionnaire: Change in Fear-Avoidance Beliefs Questionnaire is predictive of change in self-report of disability and pain intensity for patients with acute low back pain. Clinical Journal of Pain, 22, 197-203.

Grushka, M., \& Sessle, B. J. (1984). Applicability of the McGill Pain Questionnaire to the differentiation of "toothache" pain. Pain, 19, 49-57.

Haumschild, M. S., \& Haunschild, R. J. (2009). The importance of oral health in long-term care. Journal of the American Medical Directors Association, 10, 667-671.

Hayes, A. F. (2013). Introduction to mediation, moderation, and conditional process analysis. New York: Guilford Press.

Heft, M. W., Meng, X., Bradley, M. M., \& Lang, P. J. (2007). Gender differences in reported dental fear and fear of dental pain. Community Dentistry and Oral Epidemiology, 35, 421-428.

Hettema, J. M., Neale, M. C., \& Kendler, K. S. (2001). A review and meta-analysis of the genetic epidemiology of anxiety disorders. American Journal of Psychiatry, 158, 15681578.

Hildebrand, C., Fried, K., Tuisku, F., \& Johansson, C. S. (1995). Teeth and tooth nerves. Progress in Neurobiology, 45, 165-222. 
Hirsh, A. T., George, S. Z., Bialosky, J. E., \& Robinson, M. E. (2008). Fear of pain, pain catastrophizing, and acute pain perception: Relative prediction and timing of assessment. Journal of Pain, 9, 806-812.

Horjales-Araujo, E., Demontis, D., Lund, E. K., Finnerup, N. B., Borglum, A. D., Jensen, T. S., ... Vase, L. (2013). Polymorphism in serotonin receptor 3B is associated with pain catastrophizing. PLOS ONE, 8, e78889.

Hudson, J. I., \& Pope, H. G. (2007). Genetic epidemiology of eating disorders and co-occurring conditions: The role of endophenotypes. International Journal of Eating Disorders, 40, $576-578$.

Hursey, K.G., and Jacks, S.D. (1992). Fear of pain in recurrent headache sufferers. Headache, $32,283-286$.

International Association for the Study of Pain Task Force on Taxonomy. (1994). Part III: Pain terms, a current list with definitions and notes on usage. In H. Merskey \& N. Bogduk (Eds.), Classification of chronic pain (2nd ed., pp. 209-214). Seattle: IASP Press.

Janal, M. N., Glusman, M., Kuhl, J. P., \& Clark, W. C. (1994). On the absence of correlation between responses to noxious heat, cold, electrical and ischemic stimulation. Pain, 58, 403-411.

Jang, K. L., \& Shikishima, C. (2009). Behavioral genetics: Strategies for understanding the anxiety disorders. In D. McKay, J. S. Abramowitz, S. Taylor, \& G. J. G. Asmundson (Eds.), Current perspectives on the anxiety disorders: Implications for DSM-V and beyond (pp. 127-152). New York: Springer Publishing Co.

Joshipura, K., Ritchie, C., \& Douglass, C. (2000). Strength of evidence linking oral conditions and systemic disease. Compendium of Continuing Education in Dentistry, 30, 12-23. 
Kent, G. (1985). Memory of dental pain. Pain, 21, 187-194.

Klepac, R. K., Dowling, J., \& Hauge, G. (1982). Characteristics of clients seeking therapy for the reduction of dental avoidance: Reactions to pain. Journal of Behavior Therapy \& Experimental Psychiatry, 13, 293-300.

Kleinknecht, R., Klepac, R., \& Alexander L. D. (1973). Origins and characteristics of fear of dentistry. Journal of Dental Research, 86, 842-848.

Kleinknecht, R., Thorndike, R. M., McGlynn, F. D., \& Harkavy, J. (1984). Analysis of the Dental Fear Survey with cross-validation. Journal of the American Dental Association, $108,59-61$.

Klingberg, G., Berggren, U., \& Noren, J. G. (1994). Dental fear in an urban Swedish child population: Prevalence and concomitant fears. Community Dental Health, 11, 208-214.

Lang, P. J. (1968). Fear reduction and fear behavior: Problems in treating a construct. In J. M. Shlien (Ed.), Research in psychotherapy (pp. 90-102). Washington, D.C.: American Psychological Association.

Lara, A., Crego, A., \& Romero-Maroto, M. (2012). Emotional contagion of dental fear to children: The fathers' mediating role in parental transfer of fear. International Journal of Paediatric Dentistry, 22, 324-330.

Lee, K.C., Chiu, T.T.W., \& Lam, T.H. (2007). The role of fear-avoidance beliefs in patients with neck pain: relationships with current and future disability and work capacity. Clinical Rehabilitation, 21, 812-821.

Leutgeb, V., Schäfer, A., \& Schienle, A. (2011). Late cortical positivity and cardiac responsivity in female dental phobics when exposed to phobia-related pictures. International Journal of Psychophysiology, 79, 410-416. 
Li, X., Kolltveit, K. M., Tronstad, L., \& Olsen, I. (2000). Systemic diseases caused by oral infection. Clinical Microbiology Review, 13, 547-558.

Liddell, A., \& Locker, D. (1997). Gender and age differences in attitudes to dental pain and dental control. Community Dentistry and Oral Epidemiology, 25, 314-318.

Liem, E. B., Joiner, T. V., Tsueda, K., \& Sessler, D. I. (2005). Increased sensitivity to thermal pain and reduced subcutaneous Lidocaine efficacy in redheads. Anesthesiology, 102, 509514.

Liem, E. B., Lin, C., Suleman, M., Doufas, A. G., Gregg, R. G., Veauthier, J. M., ... Sessler, D. I. (2004). Anesthetic requirement is increased in redheads. Anesthesiology, 101, 279-283.

Liu, J., Garza, J. C., Li, W., \& Lu, X. Y. (2013). Melanocortin-4 receptor in the medial amygdala regulates emotional stress-induced anxiety-like behaivour, anorexia, and corticosterone secretion. International Journal of Neuropsychopharmacology, 16, 105-120.

Liu, J., Garza, J. C., Truong, H. V., Henschel, J., Zhang, W., \& Lu, X. Y. (2007). The melanocortinergic pathway is rapidly recruited by emotional stress and contributes to stress-induced anorexia and anxiety-like behavior. Endocrinology, 148, 5531-5540.

Locker, D. (2003). Psychosocial consequences of dental fear and anxiety. Community Dentistry and Oral Epidemiology, 31, 144-151.

Locker, D., \& Liddell, A. (1991). Correlates of dental anxiety among older adults. Journal of Dental Research, 70, 198-203.

MacQueen, D. A., Heckman, B. W., Blank, M. D., Janse Van Rensburg, K., Park, J. Y., ... Evans, D. E. (2014). Variation in the $\alpha 5$ nicotinic acetylcholine receptor subunit gene predicts cigarette smoking intensity as a function of nicotine content. The Pharmacogenomics Journal, 14, 70-76. 
Malouff, J. M., Rooke, S. E., \& Schutte, N. S. (2008). The heritability of human behavior: Results of aggregating meta-analyses. Current Psychology, 27, 153-161.

Marazita, M. L. (2010). GENEVA Dental Caries Project Quality Control Report. Retrieved from https://www.genevastudy.org/sites/www/content/files/datacleaning/data_cleaning_reports /Dental_Caries_Marazita_DCR_6-2-2010.pdf

Marazita, M. L., Weyant, R. J., Tarter, R., Crout, R. J., McNeil, D. W., \& Thomas, J. (2005). Family-based paradigm for investigations of oral health disparities. [Abstract]. Journal of Dental Research, 85, A-0238.

Maron, E., Hettema, J. M., \& Shlik, J. (2008). The genetics of human anxiety disorders. In R. J. Blanchard, C. D. Blanchard, G. Griebel, \& D. Nutt (Eds.), Handbook of behavioral neuroscience (Vol. 17; pp. 475-510). San Diego, CA: Elsevier Academic Press.

Martin, C. A., McNeil, D. W., Crout, R. J., Ngan, P. W., Weyant, R. J., Heady, H., \& Marazita, M. L. (2008). Oral health disparities in Appalachia: Orthodontic treatment need and demand. Journal of the American Dental Association, 139, 598-604.

McCracken, L. M., Gross, R. T., Aikens, J. \& Carnkike Jr. (1996). The assessment of anxiety and fear in persons with chronic pain: A comparison of instruments. Behaviour Research and Therapy, 34, 927-933.

McCracken, L. M., Zayfert, C., \& Gross, R. T. (1992). The Pain Anxiety Symptoms Scale: Development and validation of a scale to measure fear of pain. Pain, 50, 63-67.

McGlynn, F. D., McNeil, D. W., Gallagher, S. L., \& Vrana, S. (1987). Factor structure, stability, and internal consistency of the Dental Fear Survey. Behavioral Assessment, 9, 57-66.

McNeil, D. W., Au, A. R., Zvolensky, M, J., McKee, D. R., Klineberg, I. J., \& Ho, C. C. K. (2001). Fear of pain in orofacial pain patients. Pain, 89, 245-252. 
McNeil, D., \& Berryman, L. (1989). Components of dental fear in adults? Behaviour Research and Therapy, 27, 233-236.

McNeil, D. W., Helfer, A. J., Weaver, B. D., Graves, R. W., Kyle, B. N., \& Davis, A. M. (2011). Memory of pain and anxiety associated with tooth extraction. Journal of Dental Research, 90, 220-224.

McNeil, D. W., Kennedy, S. G., Randall, C. L., Addicks, S. H., Wright, C. D., Hursey, K. G., \& Vaglienti, R. (2017). The Fear of Pain Questionnaire-9: Brief assessment of fear of pain. Manuscript under review.

McNeil, D. W., \& Rainwater, A., J. (1998). Development of the Fear of Pain Questionnaire-III. Journal of Behavioral Medicine, 21, 389-410.

McNeil, D. W., \& Randall, C. L. (2014). Dental fear and anxiety associated with oral health care: Conceptual and clinical issues. In D. Mostofsky \& A. Fortune (Eds.), Behavioral dentistry (2nd ed., pp. 165-192). Ames, IA: John Wiley \& Sons, Inc.

McNeil, D. W., Randall, C. L., Crout, R. J., Weyant, R. J., \& Marazita, M. L. (2013). Ageassociated dental fear and fear of pain in adolescence. [Abstract]. Journal of Dental Research, 92, A-245.

McNeil, D. W., Randall, C. L., Crout, R. J., Weyant, R. J., \& Marazita, M. L. (2014). Parents' dental fear predicts adolescents' fear: Evidence for intergenerational transmission? [Abstract]. Journal of Dental Research, 93, A-156.

McNeil, D. W., Vargovich, A. M., Sorrell, J. T., \& Vowles, K. E. (2014). Environmental, emotional, and cognitive determinants of dental pain. In D. Mostofsky, A. Forgione, \& D. Giddon (Eds.), Behavioral dentistry (2nd ed., pp. 89-108). Ames, IA: John Wiley \& Sons, Inc. 
McNeil, D. W., Vargovich, A. M., Turk, C. L., \& Ries, B. J. (2012). Anxiety and fear. In V. S. Ramachandran (Ed.), Encyclopedia of human behavior (2nd ed., pp. 161-168). San Diego: Academic Press.

McNeil, D. W., Vrana, S. R., Melamed, B. G., Cuthbert, B. N., \& Lang, P. J. (1993). Emotional imagery in simple and social phobia: Fear versus anxiety. Journal of Abnormal Psychology, 102, 212-225.

Melamed, B. G., \& Williamson, D. J. (1991). Programs for the treatment of dental disorders: Dental anxiety and temporomandibular disorders. In J. Sweet, R. Rozensky, \& S. Tovian. (Eds.), Handbook of psychology in medical settings (pp. 539-565). New York: Plenum Press.

Melnick, M. (2010, December). Why surgeons dread redheads. TIME. Retrieved from http:/healthland.time.com/2010/12/10/why-surgeons-dread-red-heads/

Meng, X., Heft, M., Bradley, M., \& Lang, P. (2007). Effect of fear on dental utilization behaviors and oral health outcome. Community Dentistry and Oral Epidemiology, 35, 292-301.

Milgrom, P., Weinstein, P., \& Heaton L. J. (2009). Treating fearful dental patients: A patient management handbook (3rd ed.). Seattle, WA: Dental Behavioral Resources.

Mogil, J. S., Ritchi, J., Smith, S. B., Strasburg, K., Kaplan, L., Wallace, M. R., ... Dahan, A. (2005). Melanocortin-1 receptor gene variants affect pain and $\mu$-opioid analgesia in mice and humans. Journal of Medical Genetics, 42, 583-587.

Moore, R., Brin, H., Kirkegaard, E., Brodsgaard, I., \& Scheutz, F. (1993). Prevalence and characteristics of dental anxiety in Danish adults. Community Dentistry and Oral Epidemiology, 21, 292-296. 
Morrison, H. I., Ellison, L. F., \& Taylor, G. W. (1999). Periodontal disease and risk of fatal coronary heart and cerebrovascular diseases. Journal of Cardiovascular Risk, 6, 7-11.

Myles, P. S., Buchanan, F. F., \& Bain, C. R. (2012). The effect of hair colour on anaesthetic requirements and recovery time after surgery. Anesthesia and Intensive Care Journal, 40, 683-689.

Newton, J. T., \& Buck, D. J. (2000). Anxiety and pain measures in dentistry: A guide to their quality and application. Journal of the American Dental Association, 131, 1449-1457.

Nielsen, C. S., Stubhaug, A., Price, D. D., Vassend, O., Czajkowski, N., \& Harris, J. R. (2008). Individual differences in pain sensitivity: Genetic and environmental contributions. Pain, 136, 21-29.

Ocaňez, K. L. S., McHugh, K., \& Otto, M. W. (2010). A meta-analytic review of the association between anxiety sensitivity and pain. Depression and Anxiety, 27, 760-767.

Ochsner, K. N., Ludlow, D. H., Knierim, K., Hanelin, J., Ramachandran, T., Glover, G. C., \& Mackey, S. C. (2006). Pain, 120, 69-77.

Offenbacher, S., Katz, V., Fertik, G., Collins, J., Boyd, D., Maynor, G., McKaig, R., \& Beck, J. (1996). Periodontal infection as a possible risk factor for preterm low birth weight. Journal of Periodontology, 67, 1103-1113.

Ojima, M., Kanagawa, H., Nishida, N., Nagata, H., Hanioka, T., \& Shizukuishi, S. (2005). Relationship between attitudes toward oral health at initial office visit and compliance with supportive periodontal treatment. Journal of Clinical Periodontology, 32, 364-368.

Oosterink, F., de Jongh, A., \& Hoogstraten, J. (2009). Prevalence of dental fear and phobia relative to other fear and phobia subtypes. European Journal of Oral Sciences, 117, 135143. 
Osman, A., Breitenstein, J. L., Barrios, F. X., Gutierrez, P. M., \& Kopper, B. A. (2002). The Fear of Pain Questionnaire-III: Further reliability and validity with nonclinical samples. Journal of Behavioral Medicine, 25, 155-173.

Parr, J. J., Borsa, P. A., Fillingim, R. B., Tillman, M. D., Manini, T. M., Gregory, C. M., \& George, S. Z. (2012). Pain-related fear and catastrophizing predict pain intensity and disability independently using an induced muscle injury model. Journal of Pain, 13, 370378.

Polk, D. E., Weyant, R. J., Crout, R. J., McNeil, D. W., Tarter, R.E., Thomas, J. G., ... Marazita, M. L. (2008). Study protocol of the Center for Oral Health Research in Appalachia (COHRA) etiology study. BMC Oral Health, 8.

Poulton, R., Waldie, K. E., Thomson, W. M., \& Locker, D. (2001). Determinants of early- vs late-onset dental fear in a longitudinal epidemiological study. Behaviour Research and Therapy, 39, 777-785.

Raimondi, S. Sera, F., Gandini, F., Iodice, S., Caini, S., Maisonneuve, P., \& Fargnoli, M. C. (2008). MC1R variants, melanoma and red hair color phenotype: A meta-analysis. International Journal of Cancer, 122, 2753-2760.

Randall, C. L., McNeil, D. W., Crout, R. J., Weyant, R. J., \& Marazita, M. L. (2013). Collecting psychosocial self-report data in oral-health research: Impact of literacy level and computerized administration. Social Science and Dentistry, 2, 80-87.

Randall, C. L., McNeil, D. W., \& Stuchell, R. N. (2012). Beliefs and fears about the dentist in an emergency clinic [Abstract]. Journal of Dental Research, 91, A-1412. 
Randall, C. L., McNeil, D. W., Wiener, R. C., Crout, R. J., Weyant, R. J., \& Marazita, M. L. (2013). Fears about pain and dentistry as predictors of oral health. [Abstract]. Journal of Dental Research, 92, A-246.

Randall, C. L., McNeil, D. W., Shaffer, J. R., Crout, R. J., Weyant, R. J., \& Marazita, M. L. (2016a). Fear of pain mediates the association between MC1R genotype and dental fear. Journal of Dental Research, 95, 1132-1137.

Randall, C. L., Shaffer, J. R., McNeil, D. W., Crout, R. J., Weyant, R. J., \& Marazita, M. L. (2016b). Toward a genetic understanding of dental fear: Evidence of heritability. Community Dentistry and Oral Epidemiology, 45, 66-73.

Randall, C. L., Waddell, D., McNeil, D. W., Quentin, L., Crout, R. J., Weyant, R. J., \& Marazita, M. L. (2013, November). A brief measure of fear of pain: Assessing the factor structure and psychometric properties of the Short Form Fear of Pain Questionnaire. Poster presented at the meeting of the Association for Behavioral and Cognitive Therapies, Nashville, TN.

Ray, J., Wide Boman, U., Bodin, L., Berggren, U., Lichtenstein, P., \& Broberg, A. G. (2010). Heritability of dental fear. Journal of Dental Research, 89, 297-301.

Reimann, F., Cox, J. J., Belfer, I., Diatchenko, L., Zaykin, D. V., McHale, D. P., ... Woods, C. G. (2010). Pain perception is altered by a nucleotide polymorphism in SCN9A. Proceedings of the National Academy of Sciences of the United States of America, 107, 5148-5153.

Riley, J. L., Gilbert, G. H., \& Heft, M. W. (2006). Dental attitudes: Proximal basis for oral health disparities in adults. Community Dentistry and Oral Epidemiology, 34, 289-298. 
Roelofs, J., Peters, M.L., Deutz, J., Spijker, C., \& Vlaeen, J.W.S. (2005). The Fear of Pain Questionnaire (FPQ): Further psychometric examination in a non-clinical sample. Pain, 116, 339-346.

Sandikop, S., Agrawal, P., \& Patil, S. (2011). Relationship between dental anxiety and pain perception during scaling. Journal of Oral Science, 53, 341-348.

Scannapieco, F. A., \& Genco, R. J. (1999). Association of periodontal infections with atherosclerotic and pulmonary diseases. Journal of Periodontal Research, 34, 340-345.

Schuller, A., Willumsen, T., \& Holst, D. (2003). Are there differences in oral health and oral health behavior between individuals with high and low dental fear? Community Dentistry and Oral Epidemiology, 31, 116-121.

Shaffer, J. R., Wang, X., DeSensi, R. S., Wendell, S., Weyant, R. J., Cuenco, K. T., ... Marazita, M. L. (2012). Genetic susceptibility to dental caries on pit and fissure and smooth surfaces. Caries Research, 46, 38-46.

Shi, Q., Cleeland, C. S., Kelpstad, P., Miaskowski, C., \& Pedersen, N. L. (2010). Biological pathways and genetic variables involved in pain. Quality of Life Research, 19, 14071417.

Smith, T., \& Heaton, L. (2003). Fear of dental care: Are we making any progress? Journal of the American Dental Association, 134, 1101-1108.

Smith, S. B., Maixner, D. W., Greenspan, J. D., Dubner, R., Fillingim, R. B., Ohrbach, R., ... Diatchenko, L. (2011). Potential genetic risk factors for chronic TMD: Genetic assocaitions from the OPPERA case control study. Journal of Pain, 12, T92-101.

Smith, T., \& Moore, R. A. (1995). Repression of dental anxiety. Journal of Dental Research, 74, 144. 
Smoller, J. W., Block, S. R., \& Young, M. M. (2009). Genetics of anxiety disorders: The complex road from DSM to DNA. Depression and Anxiety, 26, 965-975.

Tabachnick, B. G., \& Fidell, L. S. (2007). Using multivariate statistics. Boston, MA: Pearson.

Thomson, W. M., Broadbent, J. M., Locker, D., \& Poulton, R. (2009). Trajectories of dental anxiety in a birth cohort. Community Dentistry and Oral Epidemiology, 37, 209-219.

F Thompson. (2011, January 18). Redheads really are... [Web log post]. Retrieved from: http://allthingswildlyconsidered.blogspot.com/2011/01/redheads-really-are.html

Tickle, M., Milsom, K., Crawford, F. I. J., \& Aggarwal, V. R. (2012). Predictors of pain associated with routine procedures performed in general dental practice. Community Dentistry and Oral Epidemiology, 40, 343-350.

Timpano, K. R., Hasler, G., Riccardi, C., Murphy, D. L., \& Schmidt, N. B. (2009). The genetics of anxiety. In G. G. Berntson \& J. T. Cacioppo (Eds.), Handbook of neuroscience for the behavioral sciences (Vol. 2; pp. 1090-1109). Hoboken, NJ: John Wiley \& Sons Inc.

Turk, D. C., \& Flor, H. (1999). Chronic pain: A biobehavioral perspective. In R. J. Gatchel \& D. C. Turk (Eds.), Psychosocial factors in pain: Critical perspectives (pp. 18-34). New York: The Guilford Press.

Turk, D.C., Robinson, J.P., \& Burwinkle, T. (2004). Prevalence of fear of pain and activity in patients with fibromyalgia syndrome. The Journal of Pain, 5, 483-490.

van Damme, S., Crombez, G., Eccleston, C., \& Roelofs, J. (2004). The role of hypervigilance in the experience of pain. In G. J. G. Asmunson, J. W. S. Vlaeyen, \& G. Crombez (Eds.), Understanding and treating fear of pain (pp. 71-90). New York: Oxford University Press. 
van Eekelen, J. A. M., Olsson, C. A., Ellis, J. A., Ang, W., Hutchinson, D., Zubrick, S. R., \& Pennell, C. E. (2011). Identification and genetic determination of an early life risk disposition for depressive disorder: Atypical stress-related behaviour in early childhood. Australian Journal of Psychology, 63, 6-17.

van Wijk, A. J. de Jongh, A., \& Lindeboon, J. A. (2010). Anxiety sensitivity as a predictor of anxiety and pain related to third molar removal. Journal of Oral and Maxillofacial Surgery, 68, 2723-2729.

van Wijk, A. J., \& Hoogstraten, J. (2003). The Fear of Dental Pain Questionnaire: Construction and validity. European Journal of Oral Sciences, 111, 12-18.

van Wijk, A. J., \& Hoogstraten, J. (2005). Experience with dental pain and fear of dental pain. Journal of Dental Research, 84, 947-950.

van Wijk, A. J., \& Hoogstraten, J. (2009). Anxiety and pain during dental injections. Journal of Dentistry, 37, 700-704.

van Wijk, A. J., \& Makkes, P. C. (2008). Highly anxious dental patients report more pain during dental injections. British Dental Journal, 205: E7.

van Wijk, A. J., McNeil, D. W., Ho, C. J., Buchanan, H., \& Hoogstraten, J. (2006). A short English version of the Fear of Dental Pain Questionnaire. European Journal of Oral Sciences, 114, 204-208.

Vasileiou, I., Giaginis, C., Klonaris, C., \& Theocharis, S. (2010). Insight into pain-inducing and -related gene expression: A challenge for development of novel targeted therapeutic approaches. Fundamental and Clinical Pharmacology, 25, 48-62.

Vassend, O., Roysamb, E., \& Nielsen, C. S. (2011). Dental anxiety in relation to neuroticism and pain sensitivity: A twin study. Journal of Anxiety Disorders, 25, 302-308. 
Verbunt, J. A., Seelen, H. A., \& Vlaeyen, J. W. S. (2004). Disuse and physical deconditioning in chronic low back pain. In G. J. G. Asmunson, J. W. S. Vlaeyen, \& G. Crombez (Eds.), Understanding and treating fear of pain (pp. 139-162). New York: Oxford University Press.

Vlaeyen, J.W., de Johng, J., Geilen, M., Heuts, P.H.T.G., van Breuklen, G. (2001). Graded exposure in vivo in the treatment of pain-related fear: a replicated single-case experimental design in four patients with chronic low back pain. Behaviour Research and Therapy, 39, 151-166.

von Frijtag, J. C., Croiset, G., Gispen, W. H., Adan, R. A. H., \& Wiegant, V. M. (1998). The role of central melanocortin receptors in the activation of the hypothalamus-pituitary-adrenalaxis and the induction of excessive grooming. British Journal of Pharmacology, 123, 1503-1508.

Vrinten, D. H., Adan, R. A. H., Groen, G. J., \& Gispen, W. H. (2001). Chronic blockade of melanocortin receptors alleviates allodynia in rats with neuropathic pain. Anesthesia and Analgesia, 93, 1572-1577.

Vrinten, D. H., Gispen, W. H., Groen, G. J., \& Adan, R. A. H. (2000). Antagonism of the melanocortin system reduces cold and mechanical allodynia in mononeuropathic rats. Journal of Neuroscience, 20, 8131-8137.

Wang, X., Shaffer, J. R., Weyant, R. J., T. Cuenco, K., DeSensi, R. S., Crout, R., .. Marazita, M. L. (2010). Genes and their effects on dental caries (tooth decay) may differ between primary and permanent dentitions. Caries Research, 44, 277-284.

Wardle, J. (1982). Fear of dentistry. British Journal of Medical Psychology, 55, 119-126. 
Williams, R., Barnett, A. H., Claffey, N., Davis, M., Gadsby, R., Kellett, M., Lip, G.Y., \& Thackray, S. (2008). The potential impact of periodontal disease on general health: A consensus view. Current Medical Research and Opinion, 24, 1635-1643.

Wilson, J. F., \& Sinisko, S. A. (1997). Increased self-reported dental anxiety following completion of a dental history questionnaire. Psychological Reports, 81, 59-62.

Wu, T., Trevisan, M., Genco, R. J., Dorn, J. P., Falkner, K. L., \& Sempos, C. T. (2000). Periodontal disease and risk of cerebrovascular disease: The first National Health and Nutrition Examination Survey and its follow-up study. Archives of Internal Medicine, 160, 2749-2755.

Xia, Y., Wikberg, J., \& Chhajlani, V. (1995). Expression of melanocortin 1 receptor in periaqueductal gray matter. Neuroreport, 16, 2193-2196.

Zubieta, J. K., Smith, Y. R., Bueller, J. A., Xu, Y., Kilbourn, M. R. Jewett, D. M., ... Stohler, C. S. (2001). Regional mu opioid receptor regulation of sensory and affective dimensions of pain. Science, 293, 311-315.

Zvolensky, M. J., Goodie, J. L., McNeil, D. W., Sperry, J. A., \& Sorrell, J. T. (2001). Anxiety sensitivity in the prediction of pain-related fear and anxiety in a heterogeneous chronic pain population. Behaviour Research and Therapy, 39, 683-696. 


\section{Footnotes}

1 'Dental care-related fear and anxiety' represents the most precise terminology to describe the phenomena that may be experienced in the context of dental and dental-related stimuli that are perceived to be threatening. As described in more detail below, dental care-related fear and dental care-related anxiety are related but distinct constructs that can occur independently of one another and/or concurrently (i.e., "mixed") in individuals (McNeil, Vargovich, Turk, \& Ries, 2012). Indeed, limited research on the etiology, assessment, and treatment of dental care-related fear and anxiety has attempted to disentangle the two, and the phenomena often are confused for one another, treated as the same, and/or considered in tandem. See McNeil \& Randall (2014) for a comprehensive commentary on this issue. For simplicity, the term 'dental care-related fear' is used throughout.

2 Of note, Caucasian/white participants (i.e., those included in the current study sample and for whom data were analyzed) were not statistically different from their non-Caucasian/white counterparts in the full COHRA1 sample on the proportion of females to males, age, years of education, socioeconomic status (i.e., the "community ladder item of the MacArthur Scale of Subjective Social Status, described below), nor level of dental care-related fear (i.e., Dental Fear Survey score, described below). However, Caucasian/white participants had, on average, lower levels of fear of pain (i.e., Fear of Pain Questionnaire-9 score, described below) than did their non-Caucasian/white counterparts $(M=23.3, S D=8.1$ for Caucasian/white participants, $M=$ $25.7, S D=9.3$ for non-Caucasian/white participants), $t(897)=2.54, p=.01$. As expected, likelihood of having one or more $M C 1 R$ variant (method of genotyping and determining of variant status described below) was greater for Caucasian/white participants than for nonCaucasian/white participants, $X^{2}(1, \mathrm{~N}=911)=14.70, p<.001$ (271 of 817 Caucasian/white 
participants and 13 of 94 non-Caucasian/white participants in the full COHRA1 sample had one or more $M C 1 R$ variant). Likewise, likelihood of having the $M C 4 R$ variant was greater for Caucasian/white participants than for non-Caucasian/white participants, $X^{2}(1, \mathrm{~N}=911)=5.00, p$ $=.025$ (207 of 817 Caucasian/white participants and 14 of 94 non-Caucasian/white participants in the full COHRA1 sample had the $M C 4 R$ variant). The same trend was observed for $O P R M 1$, $X^{2}(1, \mathrm{~N}=911)=6.75, p=.009(181$ of 817 Caucasian/white participants and 10 of 94 nonCaucasian/white participants in the full COHRA1 sample had the OPRM1 variant), and for $\operatorname{SCN} 9 A, X^{2}(1, \mathrm{~N}=911)=6.28, p=.012(259$ of 817 Caucasian/white participants and 18 of 94 non-Caucasian/white participants in the full COHRA1 sample had one or more SCN9A variant). Caucasian/white and non-Caucasian/white participants in the full COHRA1 sample did not differ significantly in their likelihood of having one of more COMT variant. The relatively large difference in size of the Caucasian/white and non-Caucasian/white subsamples is acknowledged as a limitation. 
Table 1

Linkage Disequilibrium $\left(r^{2}\right)$ Among Genotyped MC1R SNPS

\begin{tabular}{lccccc}
\hline & $\mathrm{rs} 11547464$ & $\mathrm{rs} 1805006$ & $\mathrm{rs} 1805007$ & $\mathrm{rs1805008}$ & $\mathrm{rs} 1805009$ \\
\hline $\mathrm{rs} 1110400$ & .00008 & .02 & .0004 & .002 & .0001 \\
$\mathrm{rs} 11547464$ & & .00005 & .0009 & .0009 & .00002 \\
$\mathrm{rs} 1805006$ & & .0004 & .003 & .00006 \\
$\mathrm{rs} 1805007$ & & & .003 & .0004 \\
$\mathrm{rs} 1805008$ & & & & & .0009 \\
\hline
\end{tabular}


Table 2

Mean FPQ-9 and DFS Total and Subscale Scores

\begin{tabular}{|c|c|c|c|}
\hline & $M$ & $S D$ & Range \\
\hline Total FPQ-9 & 23.2 & 8.1 & $9-45$ \\
\hline $\begin{array}{l}\text { Minor Pain } \\
\text { Subscale }\end{array}$ & 6.0 & 2.4 & $3-15$ \\
\hline $\begin{array}{l}\text { Severe Pain } \\
\text { Subscale }\end{array}$ & 9.8 & 3.7 & $3-15$ \\
\hline $\begin{array}{l}\text { Medical Pain } \\
\text { Subscale }\end{array}$ & 7.6 & 3.3 & $3-15$ \\
\hline Total DFS & 39.2 & 19.2 & $20-100$ \\
\hline $\begin{array}{l}\text { Avoidance } \\
\text { Subscale }\end{array}$ & 13.2 & 7.4 & $8-40$ \\
\hline $\begin{array}{l}\text { Fear of Specific } \\
\text { Stimuli Subscale }\end{array}$ & 14.8 & 7.5 & $6-30$ \\
\hline $\begin{array}{l}\text { Physiological } \\
\text { Arousal Subscale }\end{array}$ & 9.2 & 4.8 & $5-25$ \\
\hline
\end{tabular}

Note. $N=817$. 
Table 3

Bivariate Correlations between Demographic Variables, FPQ-9 Score, and DFS Score

\begin{tabular}{|c|c|c|c|c|}
\hline & Education & $\begin{array}{c}\text { Subjective } \\
\text { Social Status }\end{array}$ & $\begin{array}{c}\text { Total FPQ-9 } \\
\text { Score }\end{array}$ & $\begin{array}{l}\text { Total DFS } \\
\text { Score }\end{array}$ \\
\hline Age & $.15 * * *$ & $.16^{* * * *}$ & .06 & .02 \\
\hline Education & & $.19 * * *$ & -.03 & $-.11 * *$ \\
\hline $\begin{array}{l}\text { Subjective } \\
\text { Social Status }\end{array}$ & & & -.003 & -.05 \\
\hline $\begin{array}{l}\text { Total FPQ-9 } \\
\text { Score }\end{array}$ & & & & $.50 * * *$ \\
\hline
\end{tabular}

Note. Correlation statistic $=$ Pearson correlation coefficient $(r) .{ }^{* *} p<.01 . * * * p<.001$. 
Table 4

Demographic, FPQ-9, and DFS Data by Participant Sex

\begin{tabular}{|c|c|c|c|c|c|c|}
\hline & \multicolumn{3}{|c|}{ Females } & \multicolumn{3}{|c|}{ Males } \\
\hline & $M$ & $S D$ & Range & $M$ & $S D$ & Range \\
\hline Age (years) & 33.6 & 8.1 & $18-66$ & 36.7 & 9.4 & $20-67$ \\
\hline Education (years) & 13.1 & 2.3 & $7-22$ & 12.8 & 2.7 & $4-23$ \\
\hline $\begin{array}{l}\text { Subjective Social } \\
\text { Status }\end{array}$ & 5.7 & 2.0 & $1-10$ & 5.8 & 2.0 & $1-10$ \\
\hline Total FPQ-9 & 24.6 & 7.9 & $9-45$ & 21.2 & 7.8 & $9-45$ \\
\hline $\begin{array}{l}\text { Minor Pain } \\
\text { Subscale }\end{array}$ & 6.2 & 2.4 & $3-15$ & 5.6 & 2.4 & $3-15$ \\
\hline $\begin{array}{l}\text { Severe Pain } \\
\text { Subscale }\end{array}$ & 10.4 & 3.7 & $3-15$ & 8.8 & 3.6 & $3-15$ \\
\hline $\begin{array}{l}\text { Medical Pain } \\
\text { Subscale }\end{array}$ & 8.1 & 3.3 & $3-15$ & 6.7 & 3.1 & $3-15$ \\
\hline Total DFS & 40.3 & 19.6 & $20-100$ & 37.5 & 18.2 & $20-100$ \\
\hline $\begin{array}{l}\text { Avoidance } \\
\text { Subscale }\end{array}$ & 13.4 & 7.7 & $8-40$ & 12.8 & 7.0 & $8-40$ \\
\hline $\begin{array}{l}\text { Fear of Specific } \\
\text { Stimuli Subscale }\end{array}$ & 15.3 & 7.5 & $6-30$ & 13.9 & 7.2 & $6-30$ \\
\hline $\begin{array}{l}\text { Physiological } \\
\text { Arousal Subscale }\end{array}$ & 9.4 & 5.0 & $5-25$ & 8.8 & 4.4 & $5-25$ \\
\hline
\end{tabular}

Note. $N=817$. Females $n=511$. Males $n=306$. 
Table 5

Proportion of Study Sample with Risk Alleles across Genotyped MC1R SNPS

\begin{tabular}{lcc}
\hline SNP (minor allele) & $n$ & \% of sample \\
\hline rs1805008 (T) & 132 & 16.2 \\
rs1805007 (T) & 126 & 15.4 \\
rs1110400 (C) & 18 & 2.2 \\
rs1805006 (A) & 10 & 1.2 \\
rs1805009 (C) & 4 & .5 \\
rs11547464 (A) & 3 & .4 \\
\hline
\end{tabular}

Note. $N=817$. 
Table 6

Regression Models for MC1R Variant Status Predicting Dental Care-Related Fear and Fear of Pain

\begin{tabular}{|c|c|c|c|c|c|c|c|c|}
\hline \multirow[b]{2}{*}{ Predictor Variable } & \multicolumn{4}{|c|}{ DFS Total Score } & \multicolumn{4}{|c|}{ FPQ-9 Total Score } \\
\hline & $\mathrm{B}$ & $\mathrm{SE}$ & $\beta$ & $p$ & B & $\mathrm{SE}$ & $\beta$ & $p$ \\
\hline Sex & 2.93 & 1.38 & .07 & .03 & 3.45 & .57 & .21 & $<.001$ \\
\hline$M C 1 R$ Variant Status & 2.94 & 1.41 & .07 & .04 & 1.53 & .59 & .09 & .009 \\
\hline
\end{tabular}

Note. B: Unstandardized regression coefficient. SE: Standard Error. $\beta$ : Standardized regression coefficient. 
Table 7

Independent Regression Models for Prediction of Dental Care-Related Fear and Fear of Pain by Genotyped MC1R SNPs

\begin{tabular}{|c|c|c|c|c|c|c|c|c|}
\hline \multirow[b]{2}{*}{ Predictor Variable } & \multicolumn{4}{|c|}{ DFS Total Score } & \multicolumn{4}{|c|}{ FPQ-9 Total Score } \\
\hline & $\mathrm{B}$ & $\mathrm{SE}$ & $\beta$ & $p$ & $\mathrm{~B}$ & $\mathrm{SE}$ & $\beta$ & $p$ \\
\hline Sex & 2.80 & 1.38 & .07 & .04 & 3.38 & .98 & .20 & $<.001$ \\
\hline rs 1805008 & .35 & 1.82 & .007 & .85 & .68 & .75 & .03 & .36 \\
\hline Sex & 3.10 & 1.38 & .08 & .03 & 3.50 & .57 & .21 & $<.001$ \\
\hline rs1805007 & 5.94 & 1.85 & .11 & .001 & 2.37 & .76 & .11 & .002 \\
\hline Sex & 2.80 & 1.38 & .07 & .04 & 3.38 & .97 & .20 & $<.001$ \\
\hline rs 1110400 & 2.24 & 4.56 & .02 & .62 & -.17 & 1.88 & -.003 & .93 \\
\hline Sex & 2.75 & 1.40 & .07 & .05 & 3.38 & .57 & .20 & $<.001$ \\
\hline rs 1805006 & -7.88 & 6.08 & -.05 & .20 & .28 & 2.52 & .004 & .91 \\
\hline Sex & 2.84 & 1.38 & .07 & .04 & 3.39 & .57 & .20 & $<.001$ \\
\hline rs 1805009 & -14.6 & 9.58 & -1.52 & .13 & -6.24 & 3.96 & -.06 & .112 \\
\hline Sex & 2.79 & 1.38 & .07 & .04 & 3.38 & .57 & .20 & $<.001$ \\
\hline rs 11547464 & 9.03 & 11.06 & .03 & .42 & 5.87 & 4.60 & .04 & .20 \\
\hline
\end{tabular}

Note. B: Unstandardized regression coefficient. SE: Standard Error. $\beta$ : Standardized regression coefficient. Predictor variables labeled as $M C 1 R$ SNPs (by rs number) refer to presence of minor allele at indicated SNP. For the one SNP (rs1805007) for which presence of minor allele significantly predicted dental care-related fear and fear of pain, bolded above, model statistics are: $F(2,814)=7.23, p=.001, R^{2}=.02($ dental care-related fear [DFS Score] $) ; F(2,814)=22.58$, $p<.001, R^{2}=.05$ (fear of pain [FPQ-9 Score]). Threshold for statistical significance was set at $p$ $=.008$ after Bonferroni correction for multiple tests. 
Table 8

Mediation Model: Fear of Pain as Mediator between MC1R Variant Status and Dental CareRelated Fear

\begin{tabular}{lcccccc}
\hline & $\mathrm{B}$ & $\mathrm{SE}$ & $t$ & $p$ & CI (lower) & CI (upper) \\
\hline $\mathrm{X} \rightarrow \mathrm{M}(\mathrm{a})$ & 1.36 & .60 & 2.28 & $.023^{*}$ & .1917 & 2.5369 \\
$\mathrm{M} \rightarrow \mathrm{Y} \mathrm{(b)}$ & 1.17 & .07 & 16.17 & $<.001^{* *}$ & 1.0306 & 1.3153 \\
$\mathrm{X} \rightarrow \mathrm{Y}(\mathrm{c})$ & 2.80 & 1.42 & 1.97 & $.049^{*}$ & .0112 & 5.5895 \\
$\mathrm{X} \rightarrow \mathrm{Y} \mathrm{(c')}$ & 1.20 & 1.24 & .97 & .334 & -1.2356 & 3.6358 \\
\hline $\mathrm{X} \rightarrow \mathrm{M} \rightarrow \mathrm{Y}$ & 1.60 & .71 & & & .2812 & 3.0506 \\
\hline
\end{tabular}

Note. $\mathrm{X}=M C 1 R$ variant status; $\mathrm{M}=\mathrm{FPQ}-9$ score (mediator); $\mathrm{Y}=$ DFS score;

$\mathrm{B}=$ Unstandardized regression coefficient; $\mathrm{SE}=$ Standard error; $* p<.05 ; * * p<.001$. 
Table 9

Regression Model for MC4R Variant Status Predicting Dental Care-Related Fear

\begin{tabular}{lcccc}
\hline & \multicolumn{5}{c}{ DFS Total Score } \\
\cline { 2 - 5 } Predictor Variable & B & SE & $\beta$ & $p$ \\
\hline Sex & 2.60 & 1.38 & .07 & .06 \\
$M C 4 R$ Variant Status & -3.06 & 1.54 & -.07 & .04 \\
\hline
\end{tabular}

Note. B: Unstandardized regression coefficient. SE: Standard Error. $\beta$ : Standardized regression coefficient. 


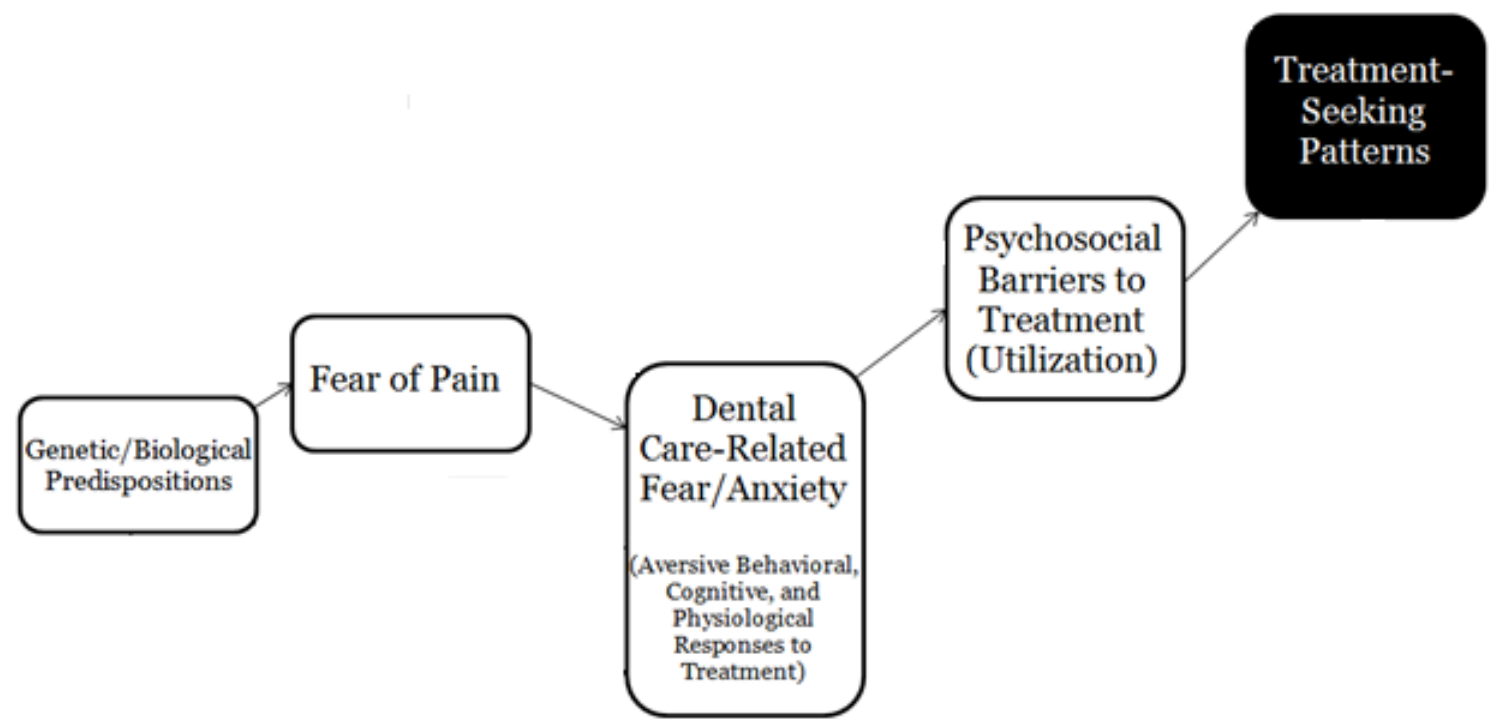

Figure 1. Study variables and their theoretical connections, drawn from a comprehensive conceptual model describing dental care-related fear. Adapted from: McNeil, D. W., \& Randall, C. L. (2014). Dental fear and anxiety associated with oral health care: Conceptual and clinical issues. In D. Mostofsky \& A. Fortune (Eds.), Behavioral dentistry (2nd ed., pp. 165-192). Ames, IA: John Wiley \& Sons, Inc. (See Appendix A). 


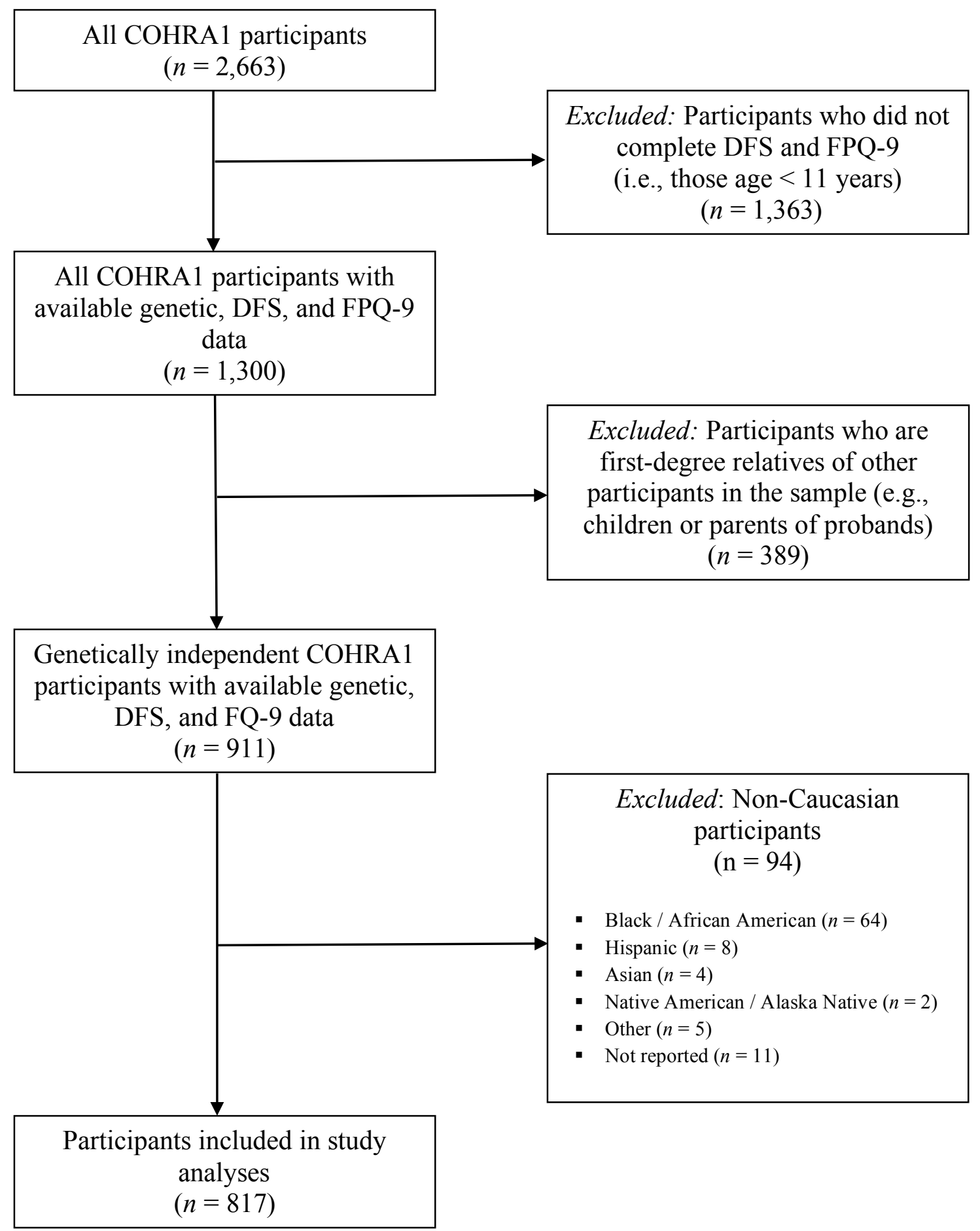

Figure 2. Selection of participants for study analyses. COHRA1 = Center for Oral Health Research in Appalachia family-based study on determinants of oral disease, cohort 1. DFS = Dental Fear Survey. FPQ-9= Fear of Pain Questionnaire-9. 


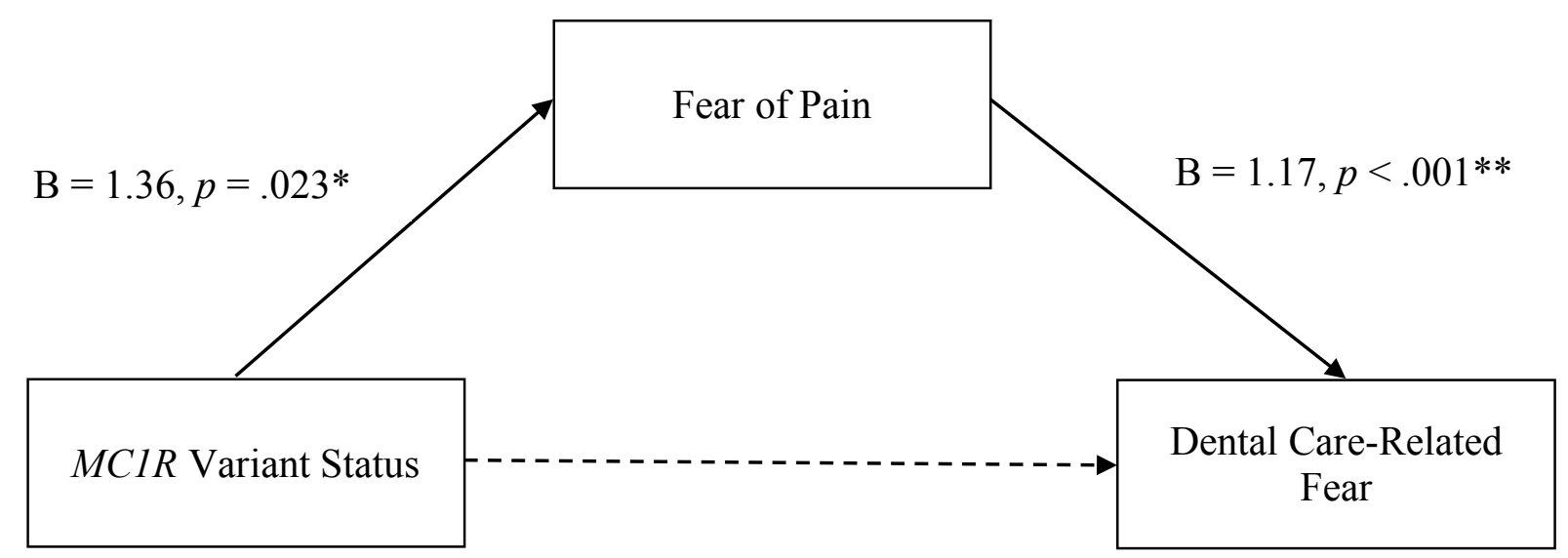

Direct effect: $\mathrm{X} \rightarrow \mathrm{Y}(\mathrm{c}), \mathrm{B}=2.80, p=.049^{*}$

Direct effect: $\mathrm{X} \rightarrow \mathrm{Y}\left(\mathrm{c}^{\prime}\right), \mathrm{B}=1.20, p=.334$

Indirect effect, $\mathrm{B}=1.60,95 \% \mathrm{CI}[.2813,3.0506]^{*}$

Figure 3. Fear of pain explains association between $M C 1 R$ variant status and dental care-related fear. $\mathrm{X}=M C 1 R$ variant status; $\mathrm{Y}=$ Dental Care-Related Fear (DFS Score); $\mathrm{B}=$ Unstandardized regression coefficient; $* p<.05 ; * * p<.001$. 
Appendix A

Conceptual Model of Dental Treatment-Seeking Patterns

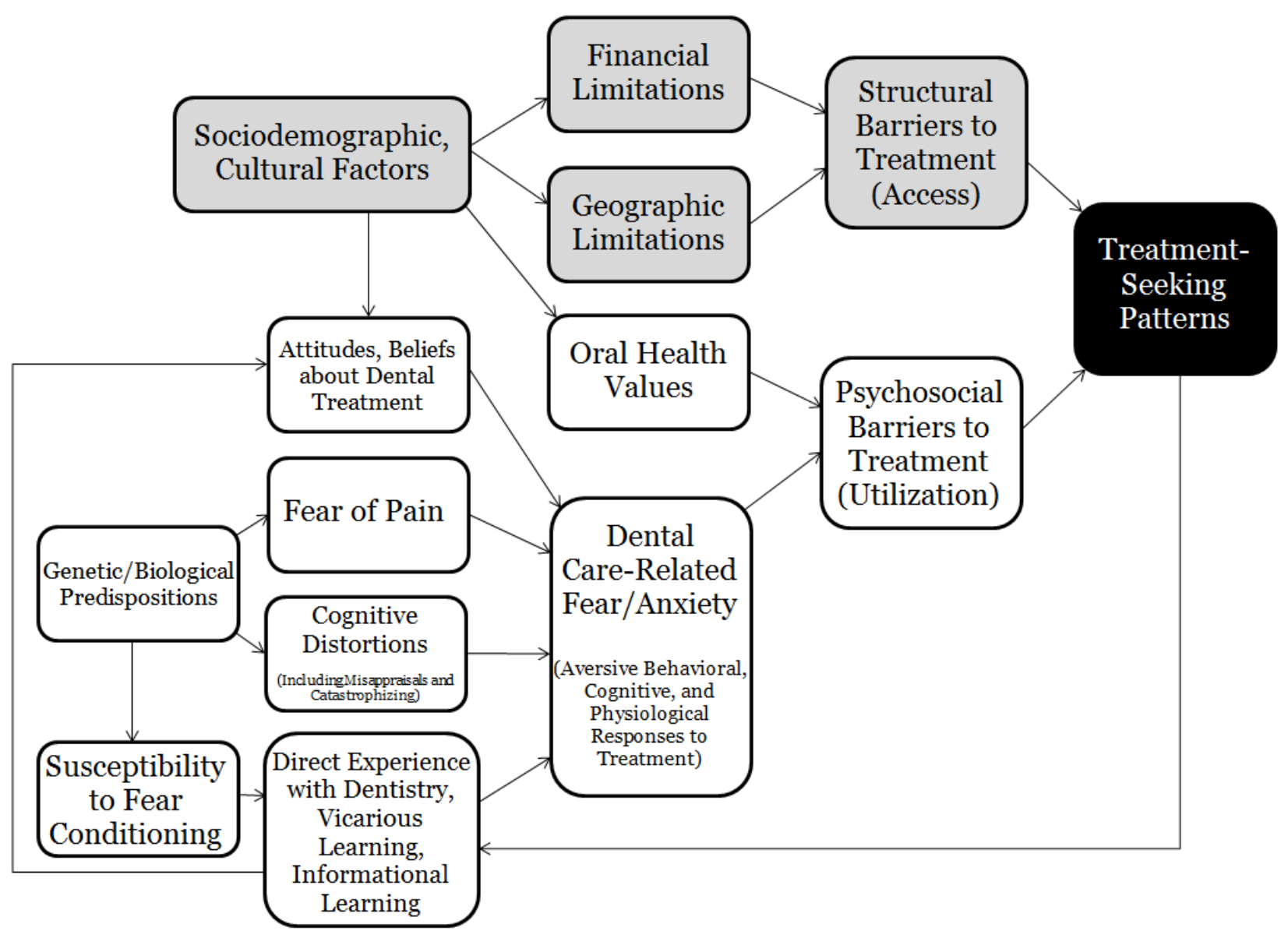

Reprinted from: McNeil, D. W., \& Randall, C. L. (2014). Dental fear and anxiety associated with oral health care: Conceptual and clinical issues. In D. Mostofsky \& A. Fortune (Eds.), Behavioral dentistry (2nd ed., pp. 165-192). Ames, IA: John Wiley \& Sons, Inc. 
Appendix B

The MacArthur Scale of Subjective Social Status, Community Ladder Item

Think of this ladder as representing where people stand in their communities.

People define community in different ways; please define it in whatever way is most meaningful to you. At the top of the ladder are the people who have the highest standing in their community. At the bottom are the people who have the lowest standing in their community.

Where would you place yourself on this ladder?

Please place a large " $X$ " on the rung where you think you stand at this time in your life, relative to other people in your community.

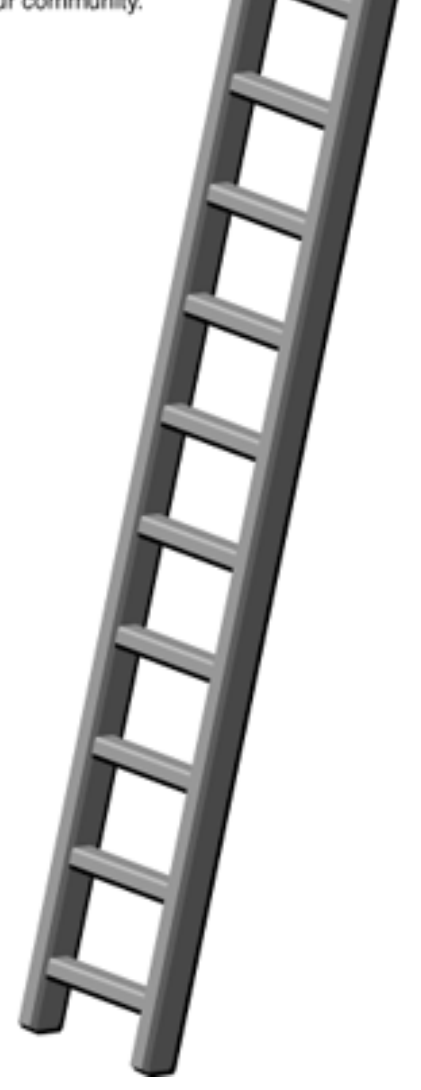

Reprinted from: Adler, N., \& Stewart, J. (2007). The MacArthur Scale of Subjective Social Status. Retrieved from: http://www.macses.ucsf.edu/research/psychosocial/subjective.php 
Appendix C

Fear of Pain Questionnaire - 9

INSTRUCTIONS: The items listed below describe painful experiences. Please look at each item and think about how FEARFUL you are of experiencing the PAIN associated with each item. If you have never experienced the PAIN of a particular item, please answer on the basis of how FEARFUL you expect you would be if you had such an experience. Circle one number for each item below to rate your FEAR OF PAIN in relation to each event.

I FEAR the PAIN associated with:

Not At All

A Little

2

2

2. Having a foot doctor remove a wart from your foot with a sharp instrument.

3. Getting a paper-cut on 1 your finger.

4. Receiving an injection 1 in your mouth.

5. Getting strong soap in both your eyes while bathing or showering.

6. Having someone slam a 1 heavy car door on your hand.

7. Gulping a hot drink before it has cooled.

8. Receiving an injection 1 in your hip/buttocks.

9. Falling down a flight of 1 concrete stairs.

2

2

2

2

2

2

2

\section{A Fair \\ Very Much \\ Extreme Amount}

3

4

5

3

4

5

3

4

5

3

4

5

3

4

5

3

4

5

3

4

5

3

4

5

3

4 5 


\section{Appendix D}

\section{Dental Fear Survey}

INSTRUCTIONS: The items in this questionnaire refer to various situations, feelings, and reactions related to dental work. Please rate your feeling or reaction on these items by using the following scales. Fill in the appropriate circle which most closely corresponds to your reaction.

$\begin{array}{cccc}\text { Never } & \begin{array}{c}\text { Once or } \\ \text { twice }\end{array} & \begin{array}{c}\text { A few } \\ \text { times }\end{array} & \text { Often } \\ \text { every time }\end{array}$

1. Has fear of dental work ever caused you to put off making an appointment?

2. Has fear of dental work ever caused you to cancel or not appear for an appointment?

When having dental work done:

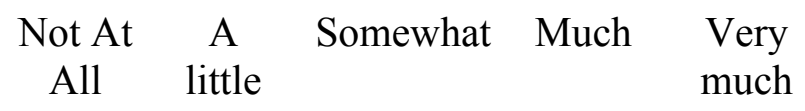

3. My muscles become tense...

4. My breathing rate increases...

5. I perspire...

6. I feel nauseated and sick to my stomach...

7. My heart beats faster... 
Following is a list of things, and situations that many people mention as being somewhat anxiety or fear producing. Please rate how much fear, anxiety, or unpleasantness each of them causes you. (If it helps, try to imagine yourself in each of these situations and describe what your common reaction is.)

$\begin{array}{ccrrr}\text { Not At } & \text { A } & \text { Somewhat } & \text { Much } & \text { Very } \\ \text { All } & \text { little } & & \text { much }\end{array}$

8. Making an appointment for dentistry.

9. Approaching the dentist's office.

10. Sitting in the waiting room.

11. Being seated in the dental chair.

12. The smell of the dentist's office.

13. Seeing the dentist walk in.

14. Seeing the anesthetic needle.

15. Feeling the needle injected.

16. Seeing the drill.

17. Hearing the drill.

18. Feeling the vibrations of the drill.

19. Having your teeth cleaned.

20. All things considered, how fearful are you of having dental work done? 